Portland State University

PDXScholar

2-18-1983

\title{
Analytical and Experimental Stresses in Concrete Pavements and Unbonded Overlays
}

\author{
Ahmad Jaber \\ Portland State University
}

Follow this and additional works at: https://pdxscholar.library.pdx.edu/open_access_etds

Part of the Construction Engineering and Management Commons, and the Structural Engineering Commons

Let us know how access to this document benefits you.

\section{Recommended Citation}

Jaber, Ahmad, "Analytical and Experimental Stresses in Concrete Pavements and Unbonded Overlays" (1983). Dissertations and Theses. Paper 3272.

https://doi.org/10.15760/etd.3262

This Thesis is brought to you for free and open access. It has been accepted for inclusion in Dissertations and Theses by an authorized administrator of PDXScholar. Please contact us if we can make this document more accessible: pdxscholar@pdx.edu. 
AN ABSTRACT OF THE THESIS OF Ahmad Jaber for the Master of Applied Science presented February 18, 1983.

Title: Analytical and Experimental Stresses in Concrete Pavements and Unbonded Overlays

APPROVED BY MEMBERS OF THE THESIS COMMITTEE:
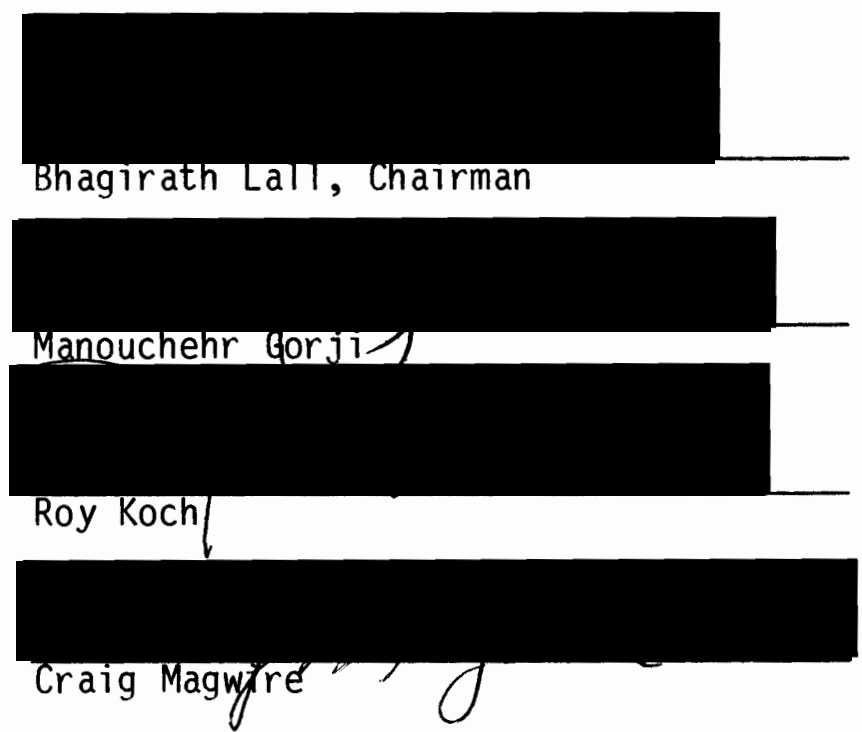

The principal objective of this study is to determine the accuracy of calculating stresses in concrete pavements and unbonded overlays under different loading conditions. The computed stresses for the single layer pavements are obtained based on Westergaard theory, the finite-element model (ILLI-SLAB), and the elastic layered model (ELSYM5). For the two-1ayer unbonded systems, stresses are estimated 
based on the finite-element theory and the Portland Cement Association design method. The experimental results for the comparison were available from a series of tests done on model scale concrete pavements and unbonded overlays. The results of present investigation show that the computed stresses for the single layer pavement slab are in good agreement with the observed stresses selected for this study, when the slab is loaded at the interior. When the pavement slab is loaded at the edge, the analytical methods give lower stresses and further investigation is recommended. On the other hand, the unbonded overlay of concrete pavement is thoroughly explored. The stresses as given by the analytical methods are, in general, of smaller magnitude than the observed ones in the unbonded overlay. The difference in the magnitude of stresses is considered attributable to the manner in which the stresses are distributed in the slab through the contact area with the load. A revised equation for the determination of the equivalent contact area is suggested to bring the analytical stresses in line with the experimental values. This revised formula is further verified in its application to some of the experimental stresses obtained from other tests and is found to give satisfactory results. 


\title{
ANALYTICAL AND EXPERIMENTAL STRESSES IN CONCRETE
}

PAVEMENTS AND UNBONDED OVERLAYS

by

AHMAD JABER

A thesis submitted in partial fulfillment of the requirements for the degree of

\author{
MASTER OF SCIENCE \\ in \\ APPLIED SCIENCE
}

Portland State University 
TO THE OFFICE OF GRADUATE STUDIES AND RESEARCH:

The members of the Committee approve the thesis of Ahmad Jaber presented February 18, 1983.

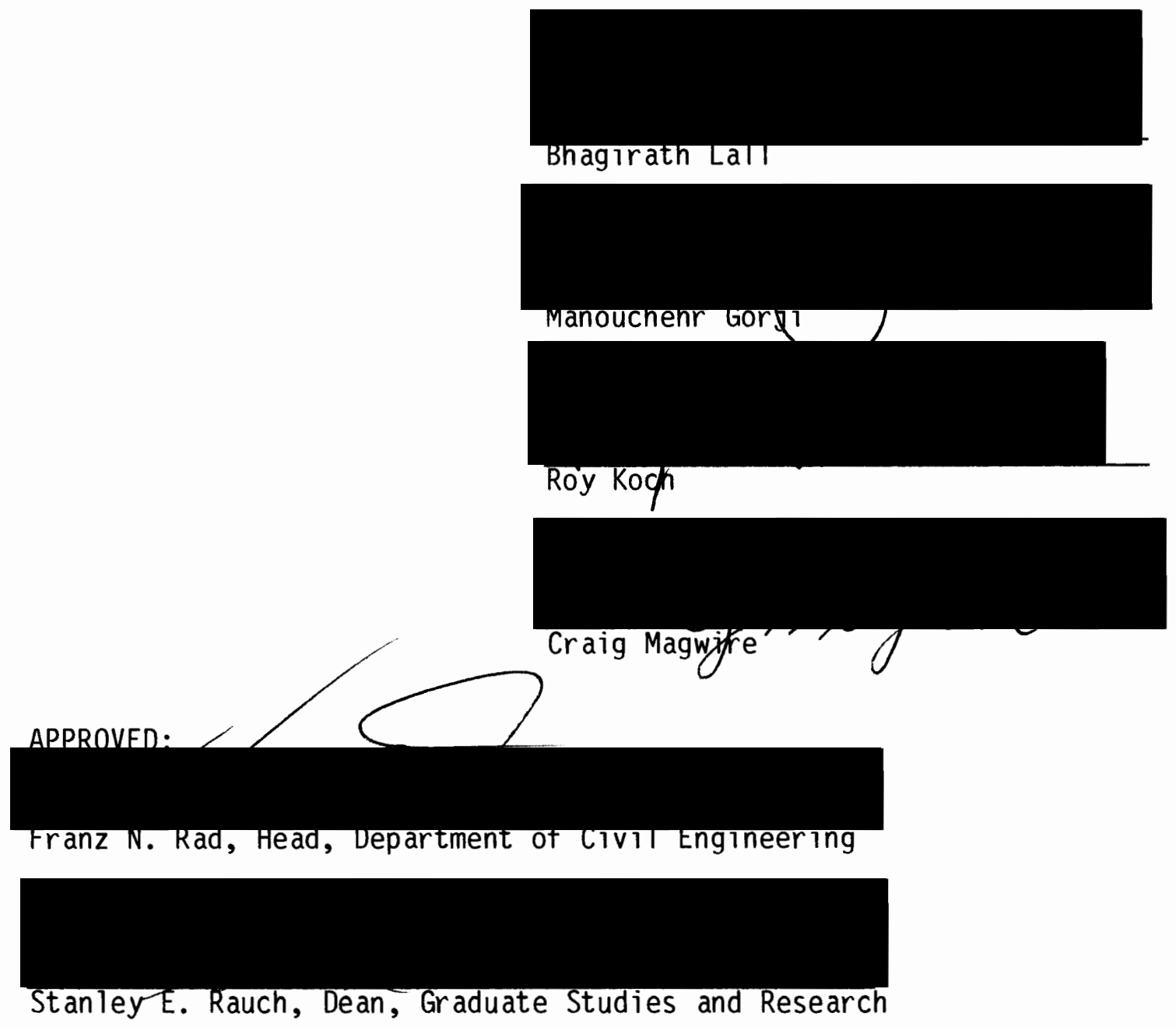


TO MY PARENTS, WIFE AND CHILDREN 


\section{ACKNOWLEDGMENTS}

The author wishes to express his great appreciation for the information, advice and encouragement he received from Dr. Bhagirath Lall, supervisor of the master's work.

The author is also grateful to members of the thesis committee for their time and effort in this endeavor.

A special thanks is also due to the consultants of the Portland State University Computer Center for their valuable assistance in the finite-element software. Gratitude is also paid to Donna Mikulic for her careful typing, to Dave Riser for drawing the figures, and to the author's wife, Nancy, for finishing the drawings and for her assistance in making valuable suggestions. 
TABLE OF CONTENTS

PAGE

ACKNOWLEDGMENTS

iv

LIST OF TABLES

viii

LIST OF FIGURES

CHAPTER

I INTRODUCTION 1

1.1 Strengthening Concrete with Concrete 1

1.1.1 Bonded Overlays 2

1.1.2 Unbonded Overlays 2

1.1.3 Partially Bonded Overlays 3

1.2 Determination of Critical Stresses 3

I I REVIEW OF AVAILABLE THEORIES FOR CONCRETE PAVEMENT/OVERLAY DESIGN 6

2.1 Westergaard Approach 6

2.1.1 Corner Load 7

2.1.2 Interior Load 9

2.1.3 Edge Load 10

2.2 Modification of Westergaard Theory 10

2.3 Finite-Element Model ILLI-SLAB 11

2.4 Elastic Layer Theory 14

2.5 Design of Concrete Overlays 16 
III VARIATION IN MATERIAL PROPERTY AND ITS

EFFECT ON STRESS ANALYSIS

3.1 General 21

3.2 Variability Characterization 22

3.3 Concrete Properties 23

3.3.1 Modulus of Elasticity 23

3.3.2 Poisson Ratio 24

3.3.3 Slab Thickness 26

3.4 Subgrade Properties 28

3.4.1 Modulus of the Subgrade Reaction and Modulus of Elasticity 28

3.4.2 Poisson Ratio 29

3.5 Overall Variation 31

IV STRESSES IN SINGLE LAYER CONCRETE SLABS 35

4.1 General 35

4.2 Effect of Bearing Area 36

4.2.1 Interior Loading 36

4.2.2 Edge Loading 39

4.3 Load-Stress Relationship 41

4.3.1 Interior Loading 41

4.3.2 Edge Loading $\quad 45$

$\checkmark \quad$ STRESSES IN TWO-LAYERED SYSTEMS $\quad 49$

5.1 General 49

5.2 Interior Loading $\quad 50$

5.3 Stress Based on the Ordinary Theory of Slabs 54 
5.4 Stress Based on the Special Theory for a Single Layer

5.5 Stress Based on the Special Theory for a Two Layer System $\quad 57$

5.6 Stress Results Based on the Modified Theory 60 5.6.1 Interior Loading $\quad 60$

$\begin{array}{lll}5.6 .2 & \text { Edge Loading } & 61\end{array}$

5.7 Effect of the Radius of Bearing Area 66

5.8 Comparison of the Specity Theory with the Portland Cement Association

5.9 Comparison of the Special Theory with Childs $\begin{array}{ll}\text { Results } & 73\end{array}$

5.10 Stress in the Underlay 75

VI CONCLUSIONS AND RECOMMENDATIONS 76

6.1 Variation in the Properties of the Materials 76

6.2 Single Slab on Subgrade $\quad 77$

6.2.1 Interior Loading 77

6.2.2 Edge Loading $\quad 77$

6.3 Overlay System 78

6.4 Suggestions for Future Work 79 


\section{LIST OF TABLES}

TABLE

PAGE

3.1 Effect on the Variation of Maximum Stress Values Due to Different Poisson Ratio

3.2 Average and Extreme Values of Stresses Based on the Variation of Parameters Used in Westergaard's Equation 


\section{LIST OF FIGURES}

FIGURE

PAGE

2.1 Conditions of loading considered by Westergaard

2.2 Finite-element model of pavement system

3.1 Stress versus modulus of elasticity for concrete interior load

3.2 Stress versus Poisson ratio for concrete slab interior load

3.3 Stress versus modulus of subgrade reaction interior load

4.1 Effect of size of bearing area on stress interior load

4.2 Effect of size of bearing area on stress edge load

4.3 Load-stress relationship for the 1 in. slab interior load

4.4 Load-stress relationship for the 1.33 in. slab interior load

4.5 Load-stress relationship for the 1 in. slab -

$$
\text { edge load }
$$

4.6 Load-stress relationship for the 1.33 in. slab edge load 
5.1 Load-stress relationship for $(1 / 1)$ overlay interior load

5.2 Load-stress relationship for (1/1.33) overlay interior load

5.3 Load-stress relationship for (1/1) overlay -

edge load

5.4 Load-stress relationship for (1/1.33) overlay edge load

5.5 Effective bearing area for the edge loading case of an overlay system 64

5.6 Stress versus radius of bearing - interior load 68

5.7 Stress versus radius of bearing - edge load 69 


\section{CHAPTER I}

\section{INTRODUCTION}

The economic growth of the 1950's and early 1960's was accompanied by rapid expansion of the existina road network in almost all of the United States. Most of these roads were constructed using Portland Cement Concrete (PCC) as the pavement surface, especially on the toll-roads. Pennsylvania, Ohio, Indiana, Illinois, Colorado, Texas, and West Virginia employed $100 \%$ concrete on their turnpikes. Other states like Kentucky and OKlahoma used concrete on large portions of their toll-road system. And, since 1956, approximately $60 \%$ of the new pavements established by the National System of Interstate and Defense Highway are constructed using concrete (Ray 1977).

Many of those built roads are now approaching the end of their design life and in need of major repairs. A long employed method for strengthening these pavements is by overlaying them with concrete, and

many design procedures have been used for this purpose (American Concrete Institute, 1967; McCullough and Monismith, 1970; McComb and Labra, 1974; Weiss, 1979).

\subsection{STRENGTHENING CONCRETE WITH CONCRETE}

Concrete pavements have a salvage value which should be used when strengthening the existing pavement. This value is becoming more and more important with the increase in costs of material and construction. 
Consequently, overlays are being used to provide a high level of structural reinforcement and for increasing the strength of existing pavement without abandoning the facility. These concrete overlays may be classified as follows:

\subsubsection{Bonded Overlays}

The principal reasons for applying bonded concrete overlays over old concrete pavements are to salvage structurally sound concrete where only the surface has deteriorated, to correct for grade and leveling of pavement, and to increase the flexural strength. Special preparation of the existing pavement is needed to ensure complete bond with the overlay. The surface must be completely clean and etched before a bonding agent of sand-cement grout or epoxy mixture is used. A fairly effective bond may be obtained if proper surface preparation and construction procedures are followed. However, due to normal ageing and differential shrinkage and expansion characteristics of two different ages of concrete, especially during the early life of overlay, loss of bond occurs; mostly along construction joints and corners (Gillete 1965).

\subsubsection{Unbonded Overlays}

At the other extreme of pavement resurfacing are the unbonded overlays where a special effort is made to prevent bonding between the overlay and base pavement. This type of overlay is normally used whenever a new jointing arrangement is desired, or where the base slab is badly distorted and some type of leveling course is required. Unbonding between layers is usually obtained by cleaning the old 
pavement of debris, excess joint sealent, and then covering it with a separation layer of polyethylene, building paper, or most commonly bituminous material. This separation layer tends to permit ease of relative movement of the two slabs of different characteristics; and hence, lowers the restrained warping stresses as well as keeps both slabs at more even temperatures than a single slab of the same thickness.

\subsubsection{Partially Bonded Overlays}

This type of overlay is widely used. In this case the overlay pavement is directly laid on the base pavement with no special effort being made to achieve bonding, nor to prevent it. All joints in the overlay should be directly over or within one foot of the joints in the base slab. The design thickness of this type of overlay is usually greater than the bonded overlay, but less than the unbonded one. The advantages of the partially bonded overlay are in the economy of material and treatment of the existing surface and in allowing some relative movement of the two slabs.

\subsection{DETERMINATION OF CRITICAL STRESSES}

A number of methods are available for the determination of critical stresses induced by static loading conditions. In general terms, the numerical solutions may be classified as: (a) use of equations; (b) use of small scale static load model tests; (c) use of computers; and (d) use of influence charts. Methods (a) and (c) are considered different approaches since, in general terms, computers are set for 
solving manually complex and tedious analysis procedures.

The previously mentioned methods are regarded as alternatives and they may give different stress results due to the different assumptions made for each of them. It is the intention of this study to combine the first three alternative procedures so as to understand the behavior of concrete pavements and concrete pavement overlays. Research work was planned to study the following main subjects:

1. Variations in the subgrade properties as well as the material used for slab construction and their effect on stress computation.

2. The variation in stress results based on the theory used.

3. The effect of the size of the bearing area on stress computations for a given load.

4. The stress behavior for single layer concrete slabs versus those of unbonded concrete overlays over concrete slabs.

5. The search for a comprehensive design procedure for the unbonded concrete overlays.

The theoretical approach for the determination of critical stresses is based on two mathematical models: plate theory and layered theory models. In the layered theory model, a uniform circular load is applied to a half-space of infinite dimensions in the plane of the plate and to several layers of finite thickness and one of infinite depth in the vertical direction. In the present investigation, the layered theory model is represented by a computer program known as the Elastic Layered System (ELSYM5) developed by Ahlborn (1972). 
On the other hand, the plate theory symbolizes a plate of finite thickness and horizontal dimensions resting on a semi-infinite half-space of another material. The most widely known work on this model is presented by Westergaard (1926). Westergaard solved for stresses and displacements in rigid pavements for three loading conditions denoted as interior, edge, and corner loading. His work, or modifications thereof, are still being used in concrete pavement design. Consequently, Westergaard equations are used throughout this study.

A finite-element model called ILLI-SLAB (Tabatabaie and Barenberg, 1980) and based on the plate theory model, is used as an additional tool in the theoretical analysis. This model is consistent with the Westergaard analysis and hence, is not considered in the variational study in the parameters that affect the computation of stresses. However, the importance of the computer program will be emphasized when considering the unbonded overlay systems.

To support the theoretical work it has to be compared to some experimental data. After analyzing some of the available studies, research done by Lall (1969) was selected as "experimental results" for two reasons: the research was conducted on a pavement model; hence the variational characteristics of the material used were held to a minimum; and, secondly, the stress results obtained for unbonded concrete overlay systems are more extensive than any other known available information for one study. 


\section{CHAPTER II}

\section{REVIEW OF AVAILABLE THEORIES FOR CONCRETE PAVEMENT/OVERLAY DESIGN}

Concrete pavement design has been an integral part of the American transportation system since 1909. During that year, Wayne county, Michigan, built the first concrete pavement after testing concrete designs, brick, and other paving materials.

Even though the design techniques for rigid pavements have progressed a longway since, most of the new design procedures are based upon Westergaard equations developed in 1926, or modification of these equations (Ray 1964). And, not until recently, the elastic layer theory approach has been used in the design of rigid pavements. However, both theories are reviewed so as to study their relations to each other and to experimental stress values.

\subsection{WESTERGAARD APPROACH}

It was not until the original Westergaard analysis was published that a rational theory for slab design became available (Westergaard 1926). In this analysis it was assumed that the slab acts as a homogeneous, isotropic, elastic solid in equilibrium and that the reaction of the subgrade is vertical only and is proportional to the deflection of the slab. This proportionality coefficient, $K$, is called the modulus of subgrade reaction. It is a measure of the stiffness of the subgrade and is given in pounds per square inch per inch of deflection (lb./in ${ }^{2} /$ in.). Another quantity introduced by Westergaard is called 
the radius of relative stiffness, $\ell$, and is a measure of the stiffness of the slab relative to that of the subgrade. This quantity has a lineal dimension (in.) and is defined mathematically as:

$$
l=\left[\frac{E h^{3}}{12\left(1-m^{2}\right) k}\right]^{1 / 4}
$$

where $E=$ modulus of elasticity of concrete in pounds per square inch

$h=$ thickness of the concrete slab in inches

$m=$ Poisson's ratio

Westergaard considered three cases of loading positions as shown in Figure 2.1.

\subsubsection{Corner Load}

For this case Westergaard showed that the maximum tensile stress occurs in the top part of the slab at a distance, from the corner along the corner bisector, of

$$
x_{1}=2 \sqrt{a_{1} l}
$$

in which

$x_{1}=$ the distance from the corner to the point of maximum stress measured along the bisector of the corner angle.

$a_{1}=a \sqrt{2}$ is the distance from the extreme slab corner to the center of the area of load application with slab edge tangent to that area.

$a$ = radius of the circular area over which the load, $P$, is assumed uniformly distributed. 

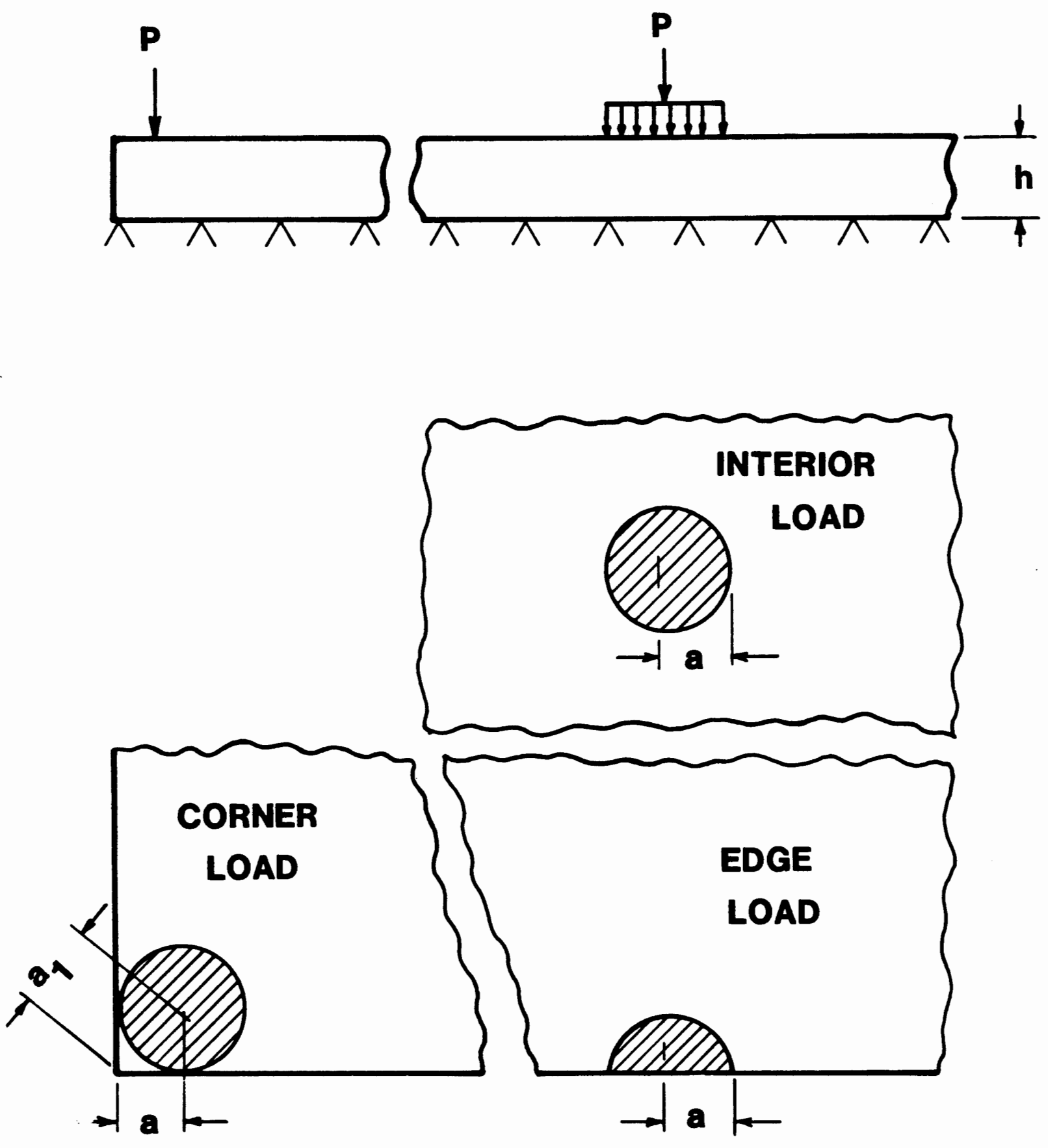

Figure 2.1 Conditions of loading considered by Westergaard 
The quantitative value of this stress, $S_{C}$, is given by:

$$
S_{C}=\frac{3 P}{h^{2}}\left[1-\left(\frac{a_{1}}{l}\right)^{0.6}\right]
$$

\subsubsection{Interior Load}

The interior loading condition assumes the load to be applied at some distance from any edge or corner of the slab. The maximum tensile stress occurs on the bottom of the slab directly under the center of the loaded area. The analysis for the case of a wheel load at a point in the interior is based on two theories. For the first theory, designated by the ordinary theory, it is assumed that a straight line drawn through the slab perpendicular to the slab remains straight and perpendicular to the neutral axis. For pavement analysis, this theory leads to a satisfactory result at all points except in the immediate neighborhood of a concentrated load. For the point load case, the special theory applies. This theory is based on only two assumptions: one is that Hooke's law applies; the other is that the material keeps its geometrical continuity at all points.

Based on these two theories the Westergaard equation for the interior loading condition is then given by

$$
S_{i}=\frac{3(1+m)}{2 \pi h^{2}}\left[\ln \frac{\ell}{b}+0.6159\right]
$$

where $S_{j}$ is the maximum critical stress

b is defined as the equivalent radius as follows:

$$
b=\sqrt{1.6 a^{2}+h^{2}}-0.675 h \text { for, } a \text {, less than } 1.72 h
$$


for larger values of $a, b$ is taken equal to $a$, that is, the ordinary theory may be used without correction. Equation (2.5) is based on experimental computation under the following assumptions:

1. The center of load, $P$, is assumed to be at the center of a circular slab.

2. The $s l a b$ is supported at the edge in such a manner that the sum of the radial and tangential bending moments is zero at every point of the edge.

With equation (2.4) written in terms of the equivalent radius, b, it is possible to express the results of the special theory in terms of the ordinary theory. This equation, when written in a more familiar form for Poisson ratio of 0.15 becomes:

$$
s_{i}=\frac{0.316 P}{h^{2}}\left[4 \log \frac{l}{b}+1.069\right]
$$

\subsubsection{Edge Load}

For this case, it is assumed that the equivalent radius, b, as defined earlier is still valid and the maximum tensile stress, $S_{e}$, occurs at the edge, and is parallel to the edge of the slab. The magnitude of this stress is:

$$
s_{e}=\frac{0.752 P}{h^{2}}\left[4 \log \frac{\ell}{b}+0.359\right]
$$

\subsection{MODIFICATION OF WESTERGAARD THEORY}

Since the original work done by Westergaard, many investigators, including Westergaard himself, have improved on the methods of stress 
computations especially for the corner loading position. These improvements came about after a series of tests made at different places in this country. The most well known is the Arlington test series.

In the early 1930's the Bureau of Public Roads conducted a series of load tests on concrete pavements at Arlington, Virginia. In those tests, measurements of stresses, deflections and subgrade pressures from loading, as well as measurement of curling due to variation in pavement temperature were made to provide a check on Westergaard equations (Teller and Sutherland 1935A, 1935B, 1935C, 1936, 1943). From these tests, it was recommended to use the following empirical formulae for the computation of the critical stresses.

$$
\begin{aligned}
& S_{c}=\frac{3 P}{h^{2}}\left[1-\left(\frac{a_{1}}{l}\right)^{1.2}\right] \\
& S_{i}=\frac{0.316 P}{h^{2}}\left[4 \log \frac{\ell}{b}+1.069\right] \\
& S_{e}=\frac{0.572 P}{h^{2}}\left[4 \log \frac{\ell}{b}+\log b\right]
\end{aligned}
$$

\subsection{FINITE ELEMENT MODEL ILLI-SLAB}

The finite-element model known as ILLI-SLAB is developed by Tabatabaie and Barenberg (1980). The model is a powerful tool for the analysis of concrete pavement systems. It is based on the classical theory of a plate on Winkler foundation. The assumptions made with regard to the concrete $s l a b$, the overlay and the subgrade are: 
1. The planes of the plate lying initially normal to the middle surface of the plate remain plane and normal to the middle surface after bending.

2. Normal stresses in the direction perpendicular to the plate surface can be disregarded for the bending solution.

3. There is no axial deformation in the middle plane of the plate and this plane remains neutral during bending.

4. Deformations are small with regard to the dimensions of the plate.

5. Each element of the slab acts as a homogeneous, isotropic, elastic solid in equilibrium. However, different elements may have different properties.

6. The subgrade behaves as a Winkler foundation.

7. In case of bonded overlay, full strain compatibility exists at the interface, and for the unbonded case there are no shear stresses at the interface.

Among these assumptions, there are others that relate to dowel bars at joints, and aggregate inter lock or Keyway as load-transfer systems. These assumptions do not relate to this thesis, and consequently are not included herein.

For modeling the concrete pavement slab, the rectangular plate element is used. Figure 2.2 shows that at each node of the element there are three displacement components: a vertical deflection perpendicular to the plate surface and in the plane of loading, and two rotations about the axis in the plane of the plate. Corresponding to these displacement components, there are force components: a vertical force and two 

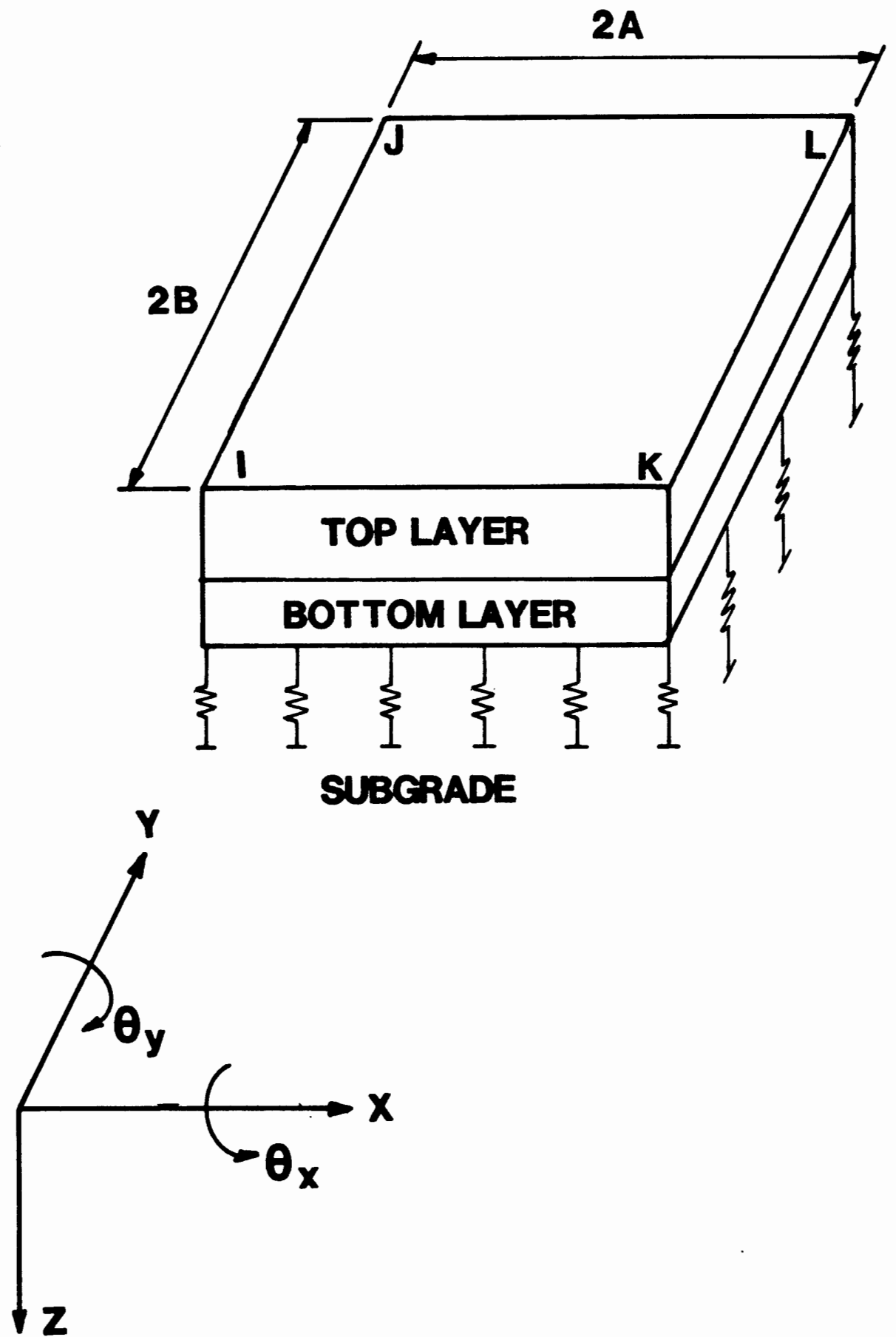

Figure 2.2 Finite-element model of pavement system 
couples. For each element, these forces and displacements can be related by matrix notations:

$$
\{P\}^{e}=\left[k_{\text {top }}+k_{\text {bottom }}+k_{\text {sub }}\right]^{e}\{D\}^{e}
$$

where $K_{\text {top }}$, $K_{\text {bottom, }}$ and $K_{\text {sub }}$, are the stiffness matrices of the top layer, the bottom layer, and the subgrade respectively; $\{P\} e$ is the force vector, and $\{0\}$ is the displacement vector of the slab element. The overall structural stiffness matrix $[K]$ is then formulated by superimposing the effect of the individual element stiffnesses to obtain:

$$
\{P\}=[K]\{D\}
$$

in which $\{P\}$ is the equivalent nodal force for a uniformly distributed load over a rectangular section of the concrete $\mathrm{Slab}$; and $\{\mathrm{D}\}$ is the resultant nodal displacements for the entire pavement system. Generalized stresses are calculated from the strain fields determined from the nodal displacements of the pavement.

\subsection{ELASTIC LAYER THEORY}

The elastic layer theory is derived from the mathematical theory of elasticity. The application of the theory to the pavement problem requires that a particular solution be found for a set of partial differential equations. The full development of the solutions was not feasible until the computer age. The major advantage of this theory is 
that it permits the complete state of stress to be determined at any point in the pavement structure. Its disadvantage is that the stress and deflection can be determined only for the interior loading case of pavement analysis.

Burmister (1943) laid much of the ground work for the solutions of elastic layers on a semi-infinite elastic subgrade. The general concept of this system requires the following assumptions.

1. The material properties of each layer are homogeneous, isotropic and elastic.

2. Each layer has a finite thickness except for the bottom layer, and all are infinite in the lateral directions.

3. Full friction is developed between layers at each interface.

4. Surface shearing forces are not present at the surface.

5. The stress solutions are characterized by two material properties for each layer: Poisson's ratio, and the elastic modulus.

Burmister's work was first based on the solution of the two-layer problem. Hank and Scrivner (1948), Peattie and Jones (1962), and others have extended Burmister's solution to include three-layered pavements. And in recent years, many computer programs have been developed. These programs permit the determination of the complete state of stress and strain at any point in a pavement structure. One of these computer programs is used in this thesis. This program is known as ELSYM5 and is developed at Berkeley, California (Ahlborn, 1972). The program is capable of finding stresses and strains, including the principal stress, at any point in the system for a 
multiple-loading condition, in a very short computer time compared to other programs. It uses a truncated series for the integration process that leads to some approximation of the results at and near the surface and at points out at some distance from the load.

One major problem with the ELSYM5, like any other program based on the elastic layered theory, is that stresses at the edge and corner of pavements cannot be evaluated. Sometimes, the stress computed by the elastic layer theory is adjusted so that it is equivalent to the stress resulting from the design load position (Treybig, H.J., et al 1977). However, adjustment factor is not considered in this thesis, since it does not give a complete picture of the analysis procedure.

\subsection{DESIGN OF CONCRETE OVERLAYS}

Several overlay design procedures have been published for concrete resurfacing of pavements. The Portland Cement Association (1965), American Concrete Institute (1967), and the Corps of Engineers (Hutchinson 1966) have detailed methods. They are all similar modifications of existing design procedures and determine the thickness of Portland Cement Concrete overlay required if a single concrete slab is used. Determination of this thickness is arrived at by using normal concrete pavement design procedures and is independent of the overlay design. The formulae used in the overlay design procedure have been developed by the Corps of Engineers for airfield pavements and have 
been used for highway pavements.

The Corps of Engineers has two empirical equations for designing concrete overlays on rigid base pavements. These are

$$
\begin{aligned}
& h_{0}=\sqrt{h^{2}-C h_{e}^{2}} \\
& h_{0}=1.4 \sqrt{h^{1.4}-C h_{e}^{1.4}}
\end{aligned}
$$

where $h_{0}=$ thickness of overlay slab in inches

$h_{e}=$ thickness of the base pavement

$h=$ full monolithic thickness of concrete pavement required for the design loading

$C=$ coefficient, depending on the condition of the existing pavement. The practice has been to use the following values of $\mathrm{C}$

$C=1.00$ when the existing pavement is in good overall structural condition

$C=0.75$ when the existing pavement has initial joint and corner cracks due to loading but no progressive structural distress or recent cracking, and

$C=0.35$ when the existing pavement is badly cracked or shattered structurally

Equation (2.13) is used where a separation course between the two pavements is required. A minimum thickness of 6 inches is recommended 
for these overlays. An overlay with a separation course is the only type that can be placed over existing pavements with severe structural defects. Equation (2.14), on the other hand, is used where the overlay pavement is placed directly on the existing pavement, and the two slabs will act as an integral unit. A minimum thickness of 5 inches is recommended for this type of overlay, and it should only be put over structurally sound pavements and limited structural defects must be repaired prior to overlay.

The thickness, $h$, of a single slab having the same structural capacity as required of the combined base and overlay slabs is determined using Westergaard (1948) equation for edge loading. The stress computed for the design load is then reduced 25 percent, an allowance for load transfer at the pavement joints.

As for bonded overlays, if a complete bond is ensured, the overlay and base slab act as a monolithic slab, and the equation for the overlay thickness is given by

$$
h_{0}=h-h_{e}
$$

This type of overlay is used only over structurally sound pavement. However, as mentioned earlier, loss of a bond does occur, especially along longitudinal construction joints and corners. In addition, careful attention should be given to the joint design to ensure that the load at the joint in either the base or overlay slab is not excessive. 
The overlay design formulae are based on the assumption that the flexural strength and modulus of elasticity of the overlay and base pavement are nearly equal. When a significant difference in flexural strength exists, an adjustment in the thickness of the base pavement should be made. This adjustment is based on Westergaard equation for a circular loaded area at the edge or interior of a pavement (Mellinger $1963)$, and is given by:

$$
h_{e e}=\left[\frac{R_{e} h_{e}^{2}(1+m)\left(3+m_{e}\right)}{R\left(1+m_{e}\right)(3+m)}\right]^{\frac{1}{2}} \text { for edge load }
$$

and

$$
h_{e e}=\left[\frac{R_{e} h_{e}^{2}(1+m)}{R\left(1+m_{e}\right)}\right]^{\frac{1}{2}} \text { for interior load }
$$

where

$$
\begin{aligned}
& h_{e e}=\text { the equivalent thickness of the base slab } \\
& R_{e}=\text { the flexural strength of the base slab } \\
& R=\text { the flexural strength of the overlay } \\
& m_{e}=\text { Poisson's ratio for the base slab }
\end{aligned}
$$

The value of Poisson's ratio is usually modified linearly by assuming a change of 0.020 for each 100 pounds per square inch change in flexural strength. Poisson's ratio for a flexural strength of 800 pounds per square inch is taken as 0.200 .

From the previous discussion, it seems that all of the design procedures for concrete overlay over concrete pavement are based on experimental work. These procedures do give a satisfactory approach to 
the immediate problem. However, it is said that the available formulae for partially bonded and unbonded overlays are sometimes very conservative. Consequently, there is a growing need for a rational, less conservative, and more clear design procedure. 
CHAPTER III

VARIATION IN MATERIAL PROPERTY AND ITS EFFECT ON STRESS ANALYSIS

\subsection{GENERAL}

In pavement design, several empirical safety and judgement factors have been applied to account for the many uncertainties involved without quantatively considering the magnitude of these uncertainties. This generally has resulted in an "overdesign" or "underdesign" depending on the situation and the level of applied safety factor. If the current deterministic pavement design procedures were modified so that the safety factors applied depended on the magnitude of the variation of concrete properties, supporting soil properties, uncertainties in traffic estimation, and other related factors, a more realistic design would be achieved.

During the past few years, several investigators have suggested that probabilistic concepts be applied to the design and analysis of Portland Cement Concrete and other structures in order to establish a certain reliability of the results (Freudenthal et al, 1966; Darter et al, 1972).

With all of these uncertainties involved it is felt that, before attempting to make direct comparison between computed and observed stresses, some background on the expected variation in the experimental stress results should be incorporated. Data obtained by Lall (1969) from the model scale tests of concrete pavements and unbonded overlays 
is used in this study since the stress results of this experimental investigation are used in the comparison analysis. These model scale tests are selected simply because the results of the research as well as procedure for setting up the investigation are available. Besides, it is among the very few available sources in terms of giving stress computations for unbonded concrete overlay systems.

A detailed description of the experimental investigation is not given in this thesis and the reader is referred to Lall (1969) and Lall and Lees (1983). However, major aspects of the model tests relating directly to the stress computations are considered, and are mentioned where, it is believed, they describe the particular situation under examination.

\subsection{VARIABILITY CHARACTERIZATION}

The variability approach requires estimation of the variations associated with the involved parameters. These variations should be individually estimated for each project. Since there is no specific estimation of the variation in the data available for Lall's (1969) study, a general variation in concrete properties, slab thickness, and subgrade support and Poisson's ratio from other laboratory test models are used. This analysis is not intended to be inclusive; its purpose is to give a feel of the behavior of concrete slabs under the variation of some uncertainties. Therefore, the variational analys is is chosen only for the interior loading case of an average one inch thick concrete slab resting on a sandy subgrade. A constant load of 473.0 
lbs. is applied on the concrete slab through a mild steel circular plate of radius of bearing of 1.316 inches. The average properties of concrete and subgrade necessary for this analysis are as follows:

Concrete Modulus of elasticity $=6.75 \times 10^{6} \mathrm{lb} / \mathrm{in}^{2}$

$$
\text { Poisson's ratio }=0.15
$$

Subgrade Modulus of subgrade reaction $=810 \mathrm{lb} / \mathrm{in}^{2} / \mathrm{in}$

Poisson's ratio $=0.50$

The data has been analyzed by investigating one variable at a time; that is, holding all others constant. By using this method, it is possible to determine the effect of the given variable on the theoretical stresses. The theoretical stresses are computed based on Westergaard formula for the interior loading case, and the Elastic Layered System denoted by ELSYM5 (Ahlborn, 1972). These theories are selected so as to study the variational effect through two different theoretical approaches: the plate theory, and the layered theory, respectively.

\subsection{CONCRETE PROPERTIES}

\subsubsection{Modulus of Elasticity}

The variations in the modulus of elasticity of concrete has been measured in numerous field and laboratory studies. In laboratory studies, the major cause of these variations are primarily attributed to the non-homogeneity of ingredients, and variation in quantities of water and cement used during construction. As mentioned earlier, the average value for the modulus of elasticity reported by Lall (1969) is 
$6.75 \times 10^{6} \mathrm{lb} / \mathrm{in}^{2}$. This value is the average result for three different tests. Kher and Darter (1973) showed that an overall coefficient of variation of 8.6 percent in the modulus of elasticity may be expected from the laboratory data. This means that the actual modulus of elasticity of the concrete is likely to be between $6.2 \times$ $10^{6} \mathrm{lb} / \mathrm{in}^{2}$ and $7.3 \times 10^{6} \mathrm{lb} / \mathrm{in}^{2}$ (probability of $65 \%$ ). Based on this range different values of this modulus are plotted showing its effect on the theoretical stress variation. These results are shown in Figure 3.1. From the figure, one can say that the average changes in the modulus of elasticity contribute a small variation in the theoretical stress. This stress variation is about $1 \%$ using Westergaard theory and $1.7 \%$ using ELSYM5. An important point that should be mentioned here is that the final critical stresses in the slab are dependent on the theory used as shown. This difference in stresses would be explained later in this work. The important aspect to study herein is the variation in stresses due to a specific theory rather than comparing theories.

\subsubsection{Poisson Ratio}

In his research, Lall (1969) assumed a value of 0.15 for the Poisson ratio of concrete. The assumption is made based on the fact that most values of Poisson ratio of concrete lie between 0.10 and 0.20 , and an average value of 0.15 seems reasonable. Yoder (1975) confirms the above assumption by stating that a Poisson ratio of 0.15 is being used most commonly for cement-treated materials (soil cement, cement-treated base, lean concrete, and Portland cement concrete). So, an average value of 0.15 for Poisson ratio is selected for this work. 


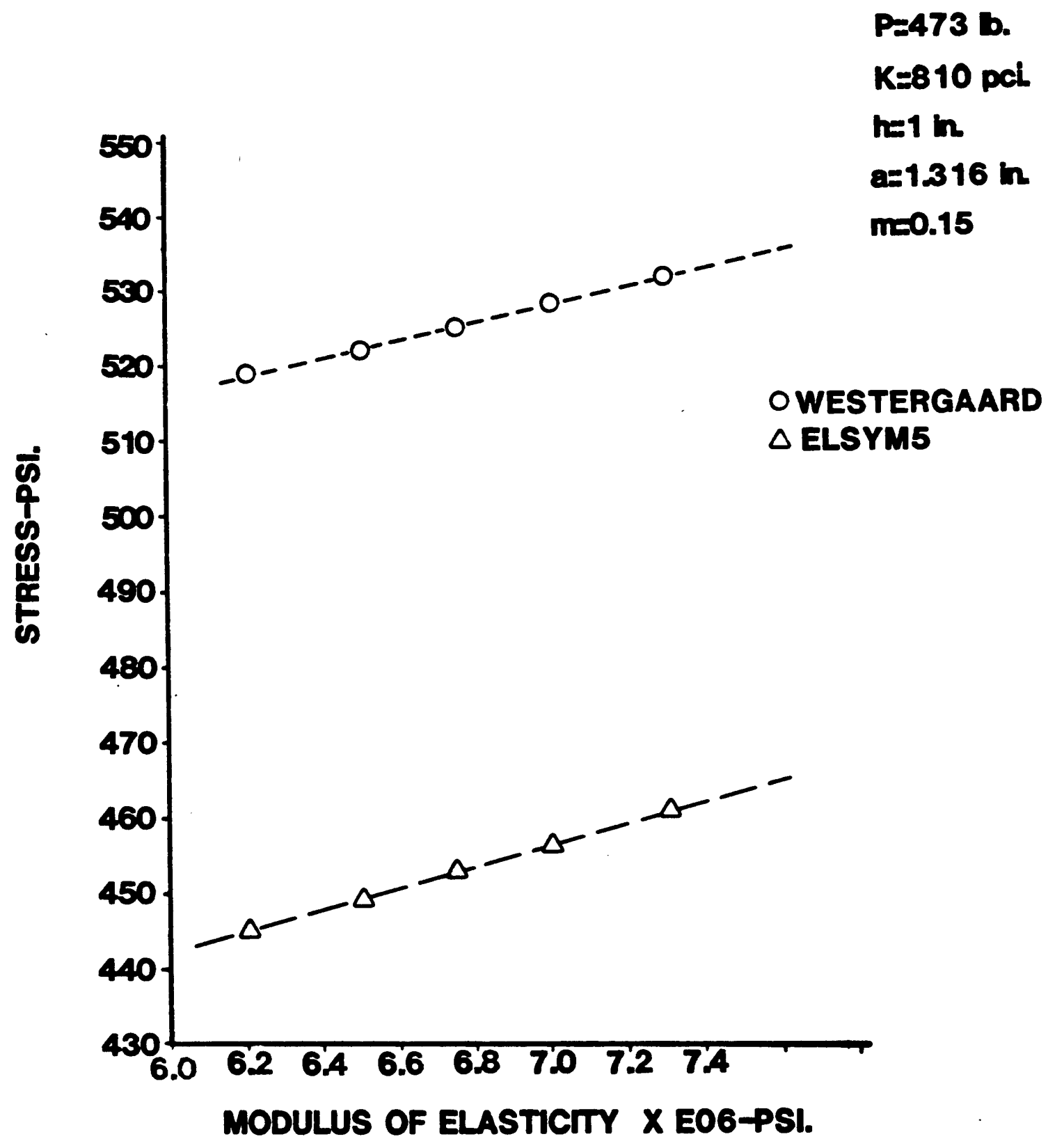

Figure 3.1 Stress versus modulus of elasticity for concrete slab-interior load. 
To study the effect of the variation in the magnitude of Poisson ratio on the computed stresses a range of values between 0.10 and 0.25 has been selected. This range includes about $95 \%$ of the various values in Poisson ratio for concrete. The results are shown in Figure 3.2. From the figure the following conclusions may be made.

1. A linear relationship exists between the theoretical stress and Poisson ratio whether using Westergaard theory, or ELSYM5.

2. If the actual Poisson ratio for the concrete was 0.25 (an extreme value), a maximum error of $9.5 \%$ and $9.1 \%$ would be involved whether using ELSYM5 or Westergaard, respectively.

If the effect of the variation in Poisson ratio on the edge stresses were analyzed, rather than the interior stress, a maximum percentage error of about 5\% would be encountered for the same range of Poisson ratio. So, it appears that the percentage of $9.5 \%$ is the maximum error whether the load is located at the interior or the edge.

\subsubsection{Slab Thickness}

Because of construction variations, the thickness of concrete slab has always been found to vary throughout a given project. However, coefficients of variations were generally small and averaged about $4.7 \%$ for field projects (Kennedy, 1976). For this model, an average value of $4 \%$ variation is assumed. The assumption is based on the fact that the slab is relatively thin ( 1 inch), and any slight variation in thickness would incur the $4 \%$ error. The thickness variation is found to induce a maximum stress error of $5.8 \%$ and $6.5 \%$ using ELSYM5 and Westergaard theory, respectively. 


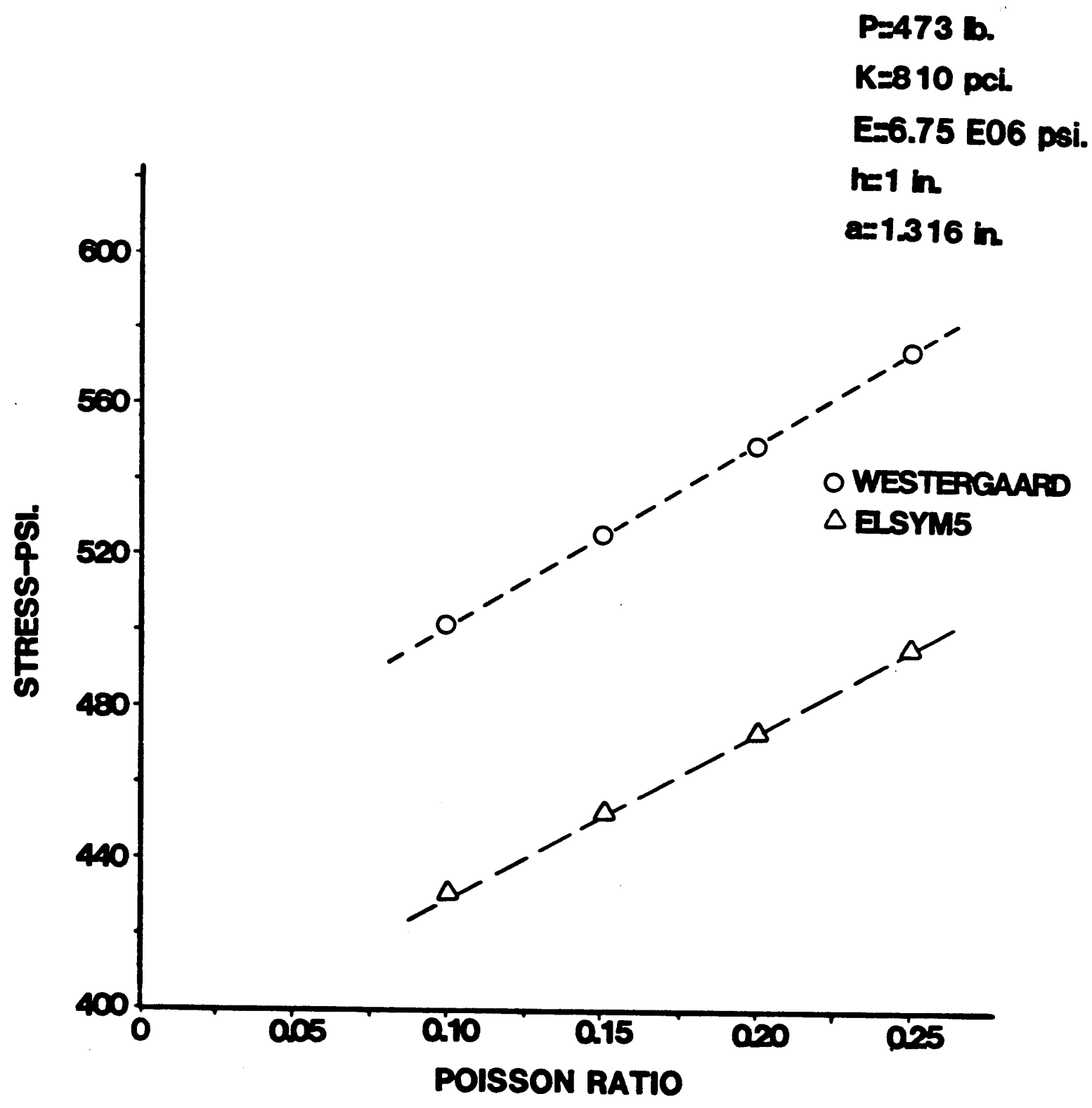

Figure 3.2 Stress versus Poisson ratio for concrete slab interior Toad 


\subsection{SUBGRADE PROPERTIES}

The performance of any pavement is affected by the characteristics of the subgrade. The ideal subgrade assumed by most theories is perfectly elastic, and its vertical deformation varies as a linear function of the vertical pressure exerted on its surface. Such a subgrade does not exist and the problem becomes one of determining by some test procedure, how nearly the soil under a given pavement approaches the ideal, and the corresponding values of the soil parameters needed for the analysis purposes. The soil parameters analyzed here are the modulus of the subgrade reaction and Poisson ratio.

\subsubsection{Modulus of the Subgrade Reaction and Modulus of Elasticity}

Among all pavement parameters, the subgrade reaction is the chief governing factor. Due to the effect of loads, repetition of loading, time of loading, and moisture content of the subgrade; and because the subgrade is by no means an ideal system a variation of up to $35 \%$ in the modulus of the subgrade reaction may be encountered (Kher and Darter, 1973). For the average value of $810 \mathrm{lb} / \mathrm{in}^{2} / \mathrm{in}$ for the modulus of the subgrade measured by Lall (1969), a range value $530-1100 \mathrm{lb} / \mathrm{in}^{2} /$ in is assumed.

To study the variation in computed stress using ELSYM5 program, it was necessary to assign a value for the modulus of elasticity of the subgrade, $E_{S}$, based on the subgrade modulus of reaction. Vaswani and Krishna (1967) recommended the following equation:

$$
E_{S}=1.18 \mathrm{Ka}
$$


For a standard plate bearing test, the plate radius is 15 inches, and the corresponding modulus of elasticity is:

$$
E_{S}=17.7 \mathrm{~K}
$$

Hence, the average value for the modulus of elasticity of the subgrade is $14350 \mathrm{lb} / \mathrm{in}^{2}$ while a range of values between $9300 \mathrm{lb} / \mathrm{in}^{2}$ and 19400 $\mathrm{lb} / \mathrm{in}^{2}$ is expected.

Figure 3.3 shows the effect of the variation in this modulus on the theoretical stresses. From the figure it can be concluded that a maximum variation in stress of $5.3 \%$ and $8.2 \%$ are obtained whether Westergaard equation or ELSYM5 are used. Another statement that can be made based on this figure is that, even though the maximum percentage of error is higher for the elastic theory, the trend in the stress variations for both approaches is about the same.

\subsubsection{Poisson Ratio}

The value of Poisson ratio of the subgrade is not required for the computation of stresses when using Westergaard equation. However, to be able to solve for stresses using the elastic layered theory a value must be assigned to it. Typical values of the Poisson ratio for the subgrade vary from 0.30 to 0.50 with most values around the 0.50 range. To check the effect of variation, different values were selected with the corresponding stress evaluated using ELSYM5. These values are shown in Table 3.1. From these tabulated stresses it seems that the maximum stress increases with the increase in the Poisson ratio up to a value of $m=0.45$. For a value of Poisson ratio 


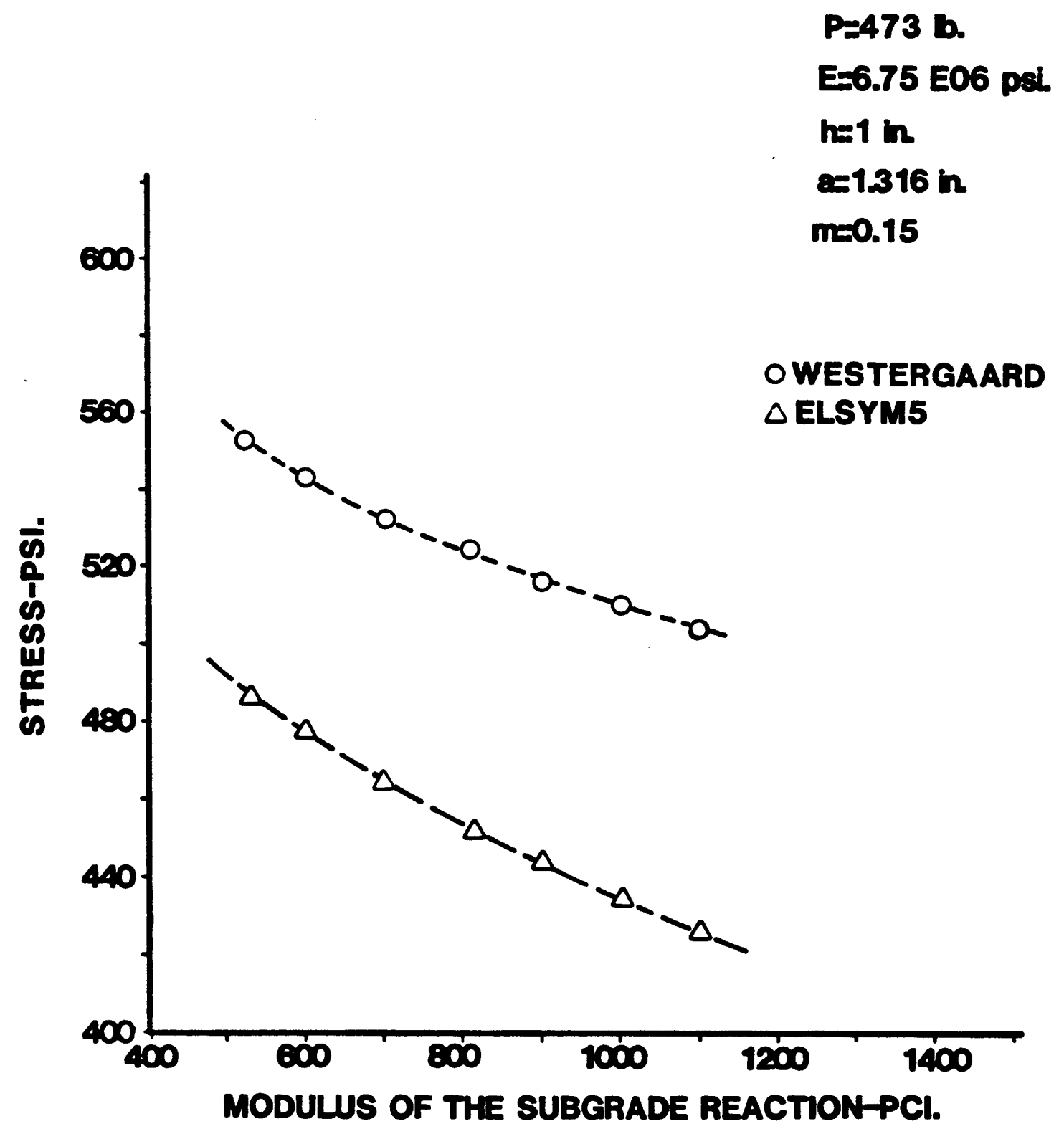

Figure 3.3 Stress versus modulus of subgrade reaction interior Toad 
of 0.45 and up the maximum stress starts decreasing. However, in general terms, the stress variation due to different values for the Poisson ratio is very small, and if a value of 0.50 is chosen, the maximum percentage error would be less than 1 percent for all of the Poisson ratio less than this value. And since the value of the modulus of elasticity derived in Equation 3.1 is based on the value of 0.5 for Poisson ratio, a value of 0.5 is selected.

\section{TABLE $\quad 3.1$}

EFFECT ON THE VARIATION OF MAXIMUM

STRESS VALUES DUE TO DIFFERENT POISSON RATIO

POISSON RATIO

$\mathrm{m}$

0.20

0.30

0.45

0.50

0.60
MAXIMUM STRESS

$\mathrm{LB} / \mathrm{IN}^{2}$

448

452

454

453

\subsection{OVERALL VARIATION}

Based on the effect in the variation of each of the variables mentioned earlier, a percentage variation in the computed stress is presented.

Due to this variational error, it is impossible to find the exact relationship between theoretical and experimental results, and some discrepancy is always present. This discrepancy is evaluated in this -section due to the effect of all of the aforementioned parameters and the interaction among them. Two extremes are chosen for this purpose. 
The upper and lower anticipated possible values in the variation of these parameters are considered, so as to calculate the maximum and minimum probable magnitudes for the maximum theoretical stresses computed by Westergaard equation and ELSYM5. These parameteric values with their corresponding stresses are shown in Table 3.2 along with the average values. From these results, it may be stated that the maximum percentage errors obtained are 14\% for Westergaard Theory and $27 \%$ for ELSYM5. The percentage error computed using ELSYM5 is much higher than the error encountered in using Westergaard theory and may be due to the following:

1. The average stress value based on ELSYM5 is much lower than that computed by Westergaard (13.7\%). Therefore, even if both theories have the same trend in stress variations, the ELSYM5 percentage error would normally be higher.

2. A linear relationship is assumed to occur between the modulus of the subgrade reaction and the modulus of elasticity. This may not be true and some error would result.

However, in general terms, it may be concluded that the percentage error in the use of the elastic layer theory is higher compared to the use of Westergaard Theory.

By the same procedure, it is possible to estimate the maximum percentage error due to the variation in the above parameters when the load is located at the edge of the slab. This variational error is calculated using equation 2.7 and found to be around $16 \%$, which is slightly higher than the variation in stress due to the interior load. So it seems that an average variation of up to $16 \%$ may be 


\begin{tabular}{|c|c|c|c|c|c|}
\hline & & 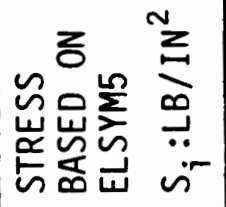 & $\stackrel{\mathscr{n}}{\mathscr{8}}$ & $\hat{n}$ & $\stackrel{\infty}{m}$ \\
\hline \multirow{7}{*}{$\begin{array}{l}\stackrel{N}{m} \\
\dot{m} \\
\frac{\omega}{E}\end{array}$} & \multirow{6}{*}{ 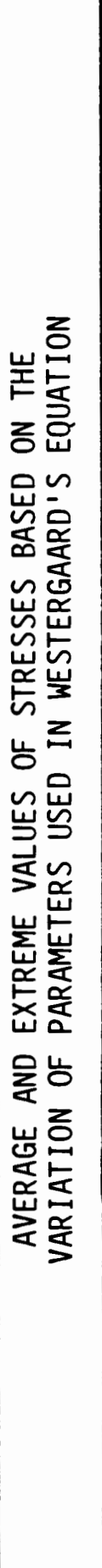 } & 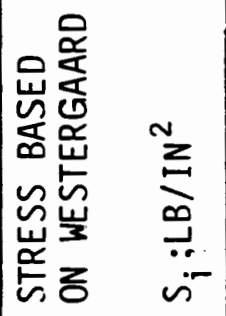 & స్ & 요 & $\begin{array}{l}\infty \\
0 \\
\end{array}$ \\
\hline & & 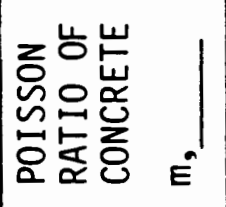 & $\stackrel{n}{\stackrel{n}{0}}$ & 峁 & $\begin{array}{l}0 \\
\dot{0}\end{array}$ \\
\hline & & 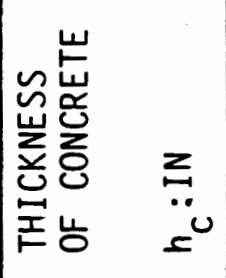 & $\stackrel{\circ}{-}$ & $\begin{array}{l}\mathscr{8} \\
\dot{0}\end{array}$ & $\underset{-}{\stackrel{8}{\circ}}$ \\
\hline & & 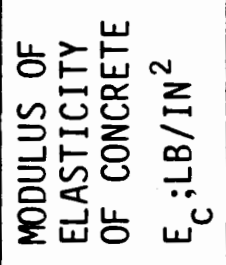 & 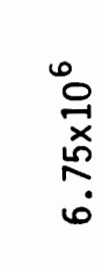 & $\begin{array}{l}0 \\
\stackrel{1}{x} \\
\stackrel{p}{n} \\
r\end{array}$ & $\begin{array}{l}0 \\
\stackrel{0}{\not} \\
\stackrel{0}{0} \\
\dot{0}\end{array}$ \\
\hline & & 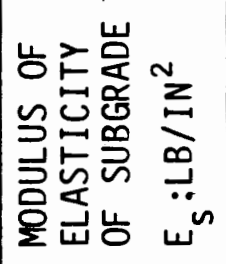 & 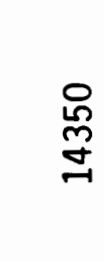 & ᄋ্লি & $\begin{array}{l}\text { ᄋ } \\
\text { 엄 }\end{array}$ \\
\hline & & 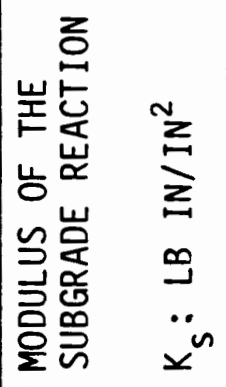 & $\underset{\infty}{\infty}$ & గ్లి & $\begin{array}{l}\text { ᄋ } \\
\text { 겅 }\end{array}$ \\
\hline & & & 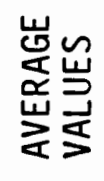 & $\begin{array}{l}\sim \\
\text { 品 } \\
\text { 号品 }\end{array}$ & 怘䀠 \\
\hline
\end{tabular}


present when comparing the observed stress results with the Westergaard Theory. Similarly, if the observed stresses are compared with ELSYM5 results, an average variation of up to $27 \%$ may occur.

As it has been shown, almost every measurable factor used in pavement design has some level of uncertainty. These uncertainties should be carefully analyzed so as to obtain the extent of their effect on the design of pavements. The results are a means of understanding the safety factors involved in the design procedure, so as to avoid overdesigning and underdesigning. Strict reliance on these results should not be exercised unless they are accompanied by sound engineering judgement. 


\section{CHAPTER IV}

\section{STRESSES IN SINGLE LAYER CONCRETE SLABS}

\subsection{GENERAL}

The Westergaard equations for the computation of deflections and stresses in concrete pavements formed the basis of pavement design. These equations, in many instances, gave satisfactory results; and they were largely applied to concrete pavement structures. With the rapid growth of the computer industry, the reliance on these equations has decreased drastically. However, due to their importance, it is decided that the relations between computed and experimental stresses should include a comparison with Westergaard's work as well.

The stress comparisons are made for the models of 1 inch and 1.33 inch thick slabs laying on the sandy subgrade. The material properties of concrete and subgrade are given in chapter three. The actual horizontal dimensions of the model were chosen based on Westergaard (1926) work; which implies that if the length of the slab is greater or equal to eight times the radius of relative stiffness, then it would behave as a slab of infinite length. For properties and thicknesses of slabs as given, a slab model of $4.4 \mathrm{ft} \times 9.1 \mathrm{ft}$ was selected by Lall (1969). These dimensions would enable the plate to act as if it were a slab of infinite dimensions when loaded at the interior, and semi-infinite behavior for edge loading case. 
For the finite-element model a $6.5 \mathrm{ft} \times 6.5 \mathrm{ft}$ square slab is assumed. A square slab is selected to keep the symmetry in stress calculations for the interior loading case. The theoretical dimensions are assumed because if the actual model dimensions were to be used then the theoretical tangential stresses at the long edge of the slab may be high enough to offset the infinite behavior assumption when the slab is loaded at the interior.

As mentioned previously, the actual load is distributed over a circular area. The finite-element program, however, considers a rectangular distribution of the load. This distribution is assumed so that the evaluation of the equivalent nodal forces of the load would be simple; and relies on the same matrix components used for the evaluation of the stiffness matrix of the rectangular element of the slab. To reduce the effect of this difference in this load distribution on the stress computations, the circular load used is assumed equal to a rectangular load of the same area.

\subsection{EFFECT OF BEARING AREA}

One of the early steps in this analysis was to study the effect of the radius of bearing area, over which the load is distributed, on maximum stress for both the interior and edge loading cases.

\subsubsection{Interior Loading}

Figure 4.1 shows the effect of the size of the bearing area on the maximum stress observed at the interior, when the load is applied in this position. The applied load is taken constant and shown on the 


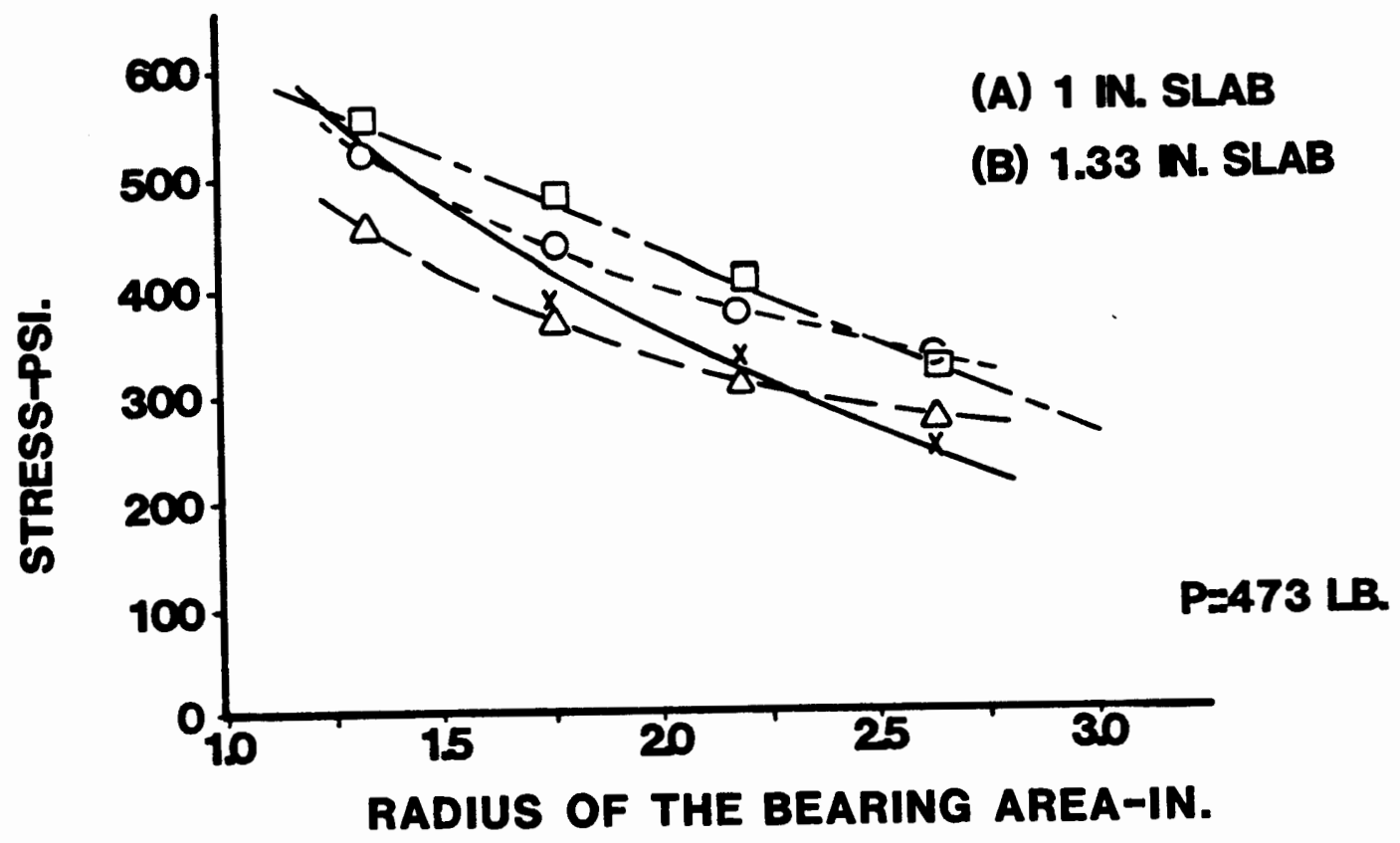

(A)

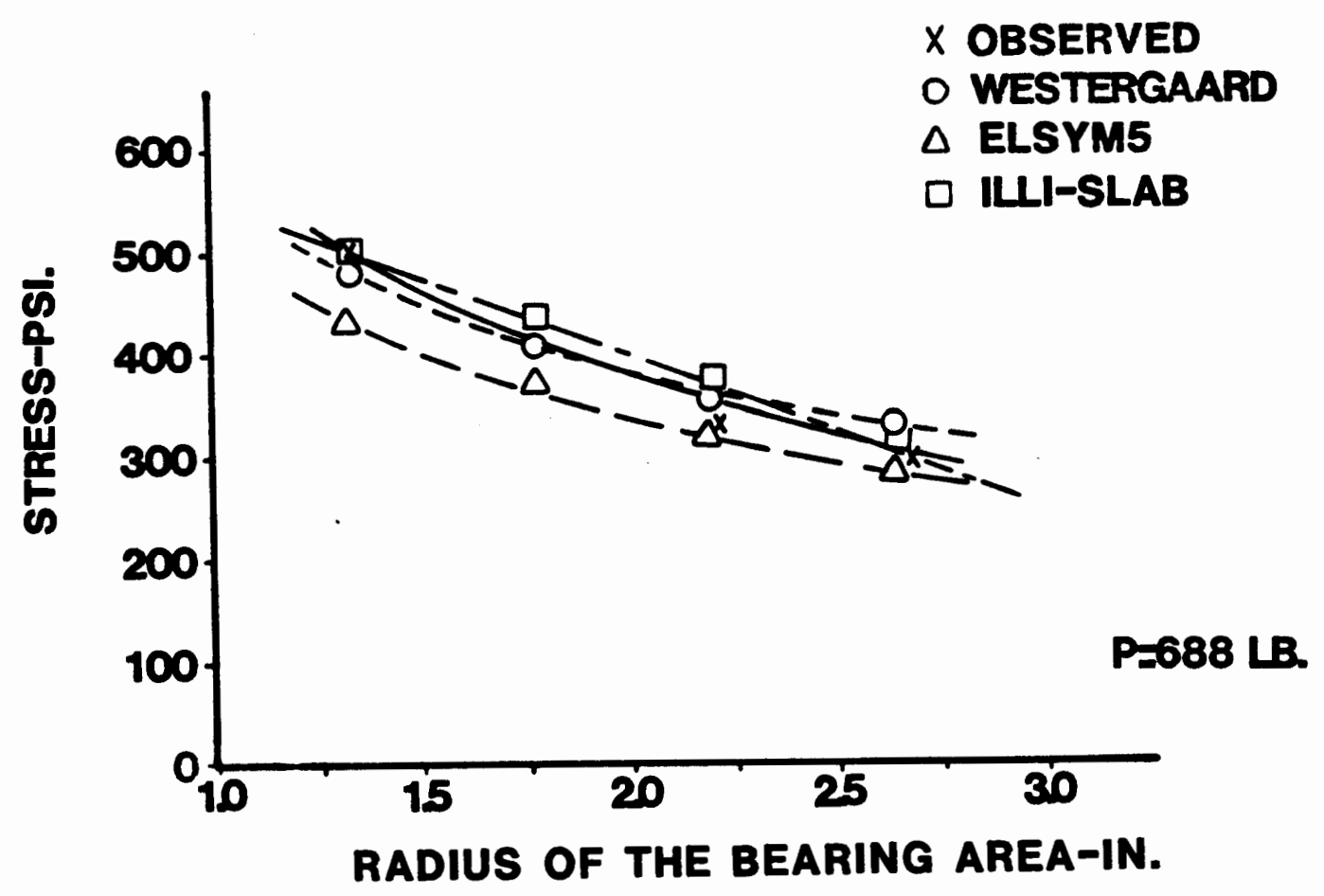

(B)

Figure 4.1 Effect of size of bearing area on stress interior Toad 
figure. The figure shows that the relative variation of stress seems compatible and within acceptable experimental results for the different theories used. Stress computations based on Westergaard formula, for example, agree closely with the experimental results. On the other hand, the elastic layered theory results of ELSYM5 are in the lower range with an almost identical curvature as Westergaard. This stress difference may be attributed to the following:

1. The value of the modulus of elasticity of the subgrade is estimated from the modulus of the subgrade reaction using equation 3.2. The actual value of this modulus may be less than estimated. Consequently, the corresponding stress calculations based on ELSYMS may be higher than what the figure shows.

2. The ELSYM5 program assumes full friction to occur at the interface. In constructing the model a sandy subgrade was used which is known to reduce the effect of the friction force (Timms, 1963; Lepper and Kim, 1963). Therefore, stresses in the actual model would be higher than predicted by ELSYM5.

3. The elastic layered theory, for the model dimensions used, may give low stress values. This may be due to the thinness of the $\mathrm{slab}$ model.

As for the results based on the ILLI-SLAB program, they seem slightly conservative. This variation could be due to "one of two reasons:

1. The horizontal dimensions used for the finite element are assumed as $6.5 \mathrm{ft}$ by $6.5 \mathrm{ft}$ while the actual dimensions of the 
model are $4.4 \mathrm{ft}$ by $9.1 \mathrm{ft}$. Again, the square slab of the above dimensions is used to ensure the infinite behavior of the slab for the interior loading conditions.

2. The actual load applied to the slab is distributed over a circular area. This area is replaced theoretically by a square section of the same area under the same loading conditions to be used by the finite element program.

\subsubsection{Edge Loading}

The effect of the size of the bearing area on the maximum stress when the slab is loaded at the edge is shown in Figure 4.2. The figure shows that the trend in the variation of all three curves is identical for both the 1 inch and 1.33 inch concrete slabs. However, the experimental stress results are higher than that predicted by Westergaard and the ILLI-SLAB. The difference could be attributed to the warping of the slabs. Because of moisture gradient an upward curling at the corners and edges of the slabs is observed by Lall (1969) and Lall and Lees (1983). This moisture differential may have affected the state of stress through restrained warping of the slab (Teller and Sutherland 1943).

To summarize, one may state that regardless of the theory used for the determination of stress for different radii of bearing area, the following conclusions may be drawn:

1. Under the same loading conditions, stress decreases with the increase in the radius of bearing area whether dealing with the interior or edge loading case. 


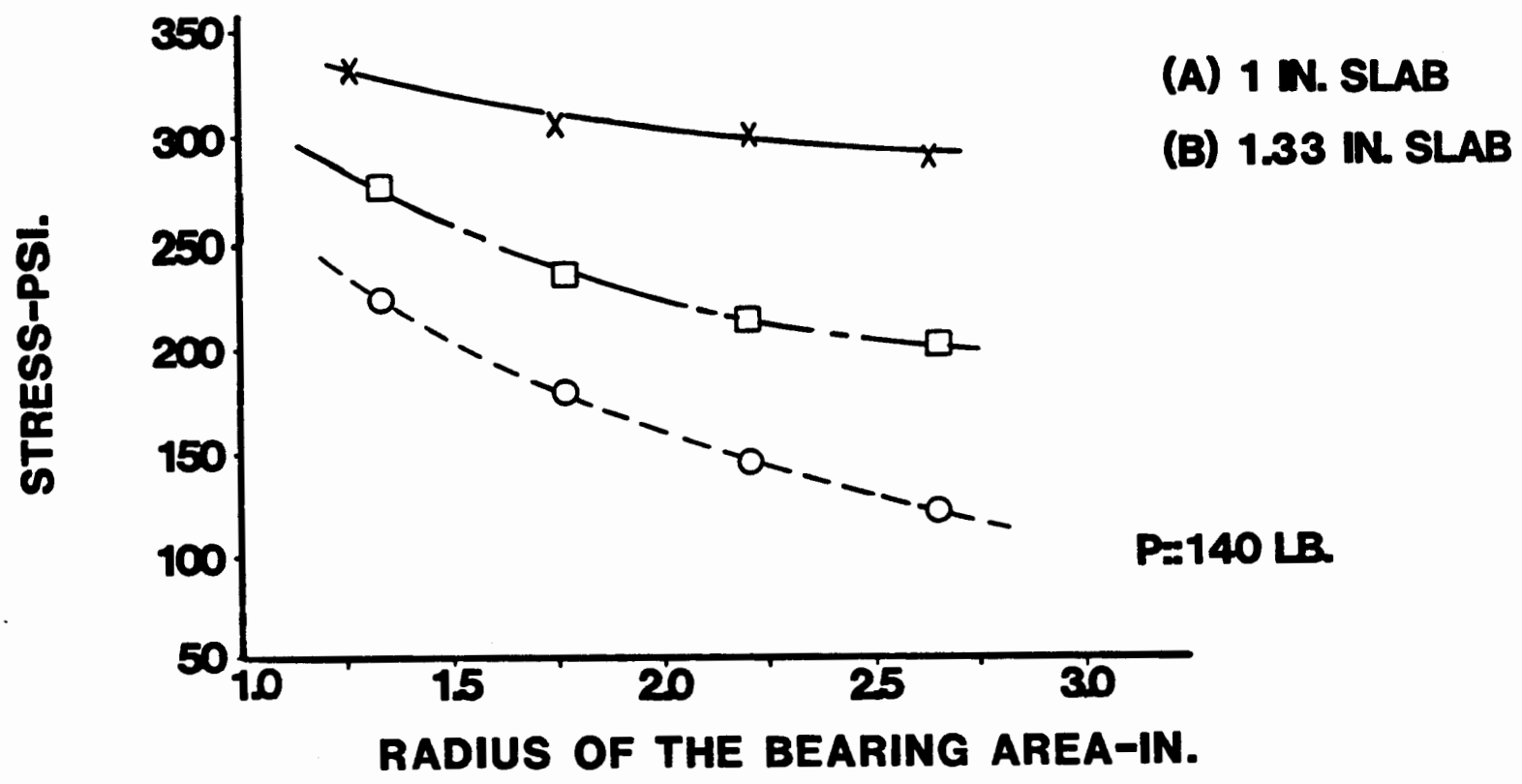

(A)

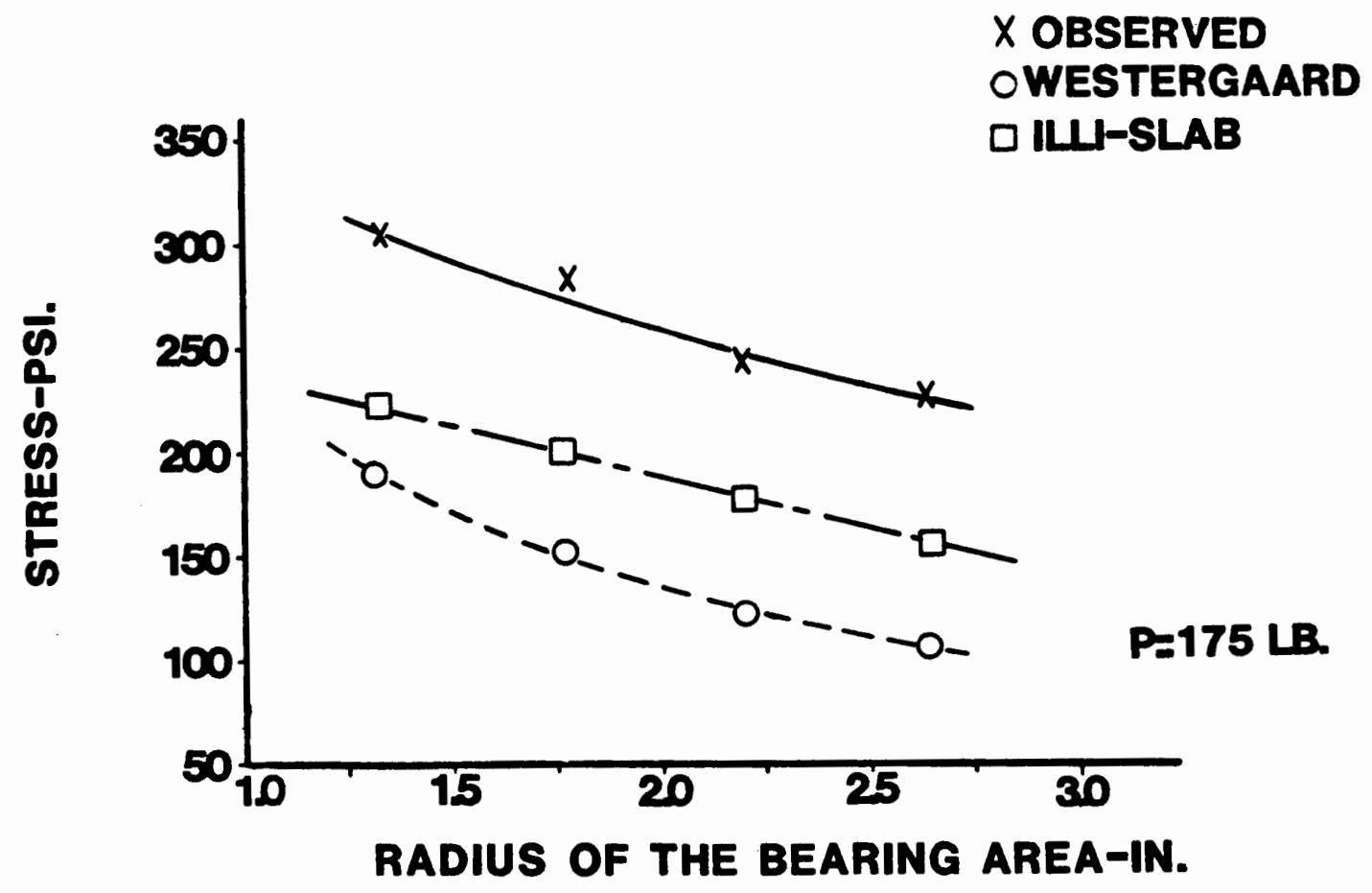

(B)

Figure 4.2 Effect of size of bearing area on stress edge load 
2. The critical stresses in the 1.33 inch slab are lower than those of the 1 inch slab, even when the loading on the thicker slab is higher than the thinner one. This statement seems valid for both the interior and edge loading cases, for the magnitude of loading considered.

3. The ILLI-SLAB results are, in general, higher than those computed by Westergaard. The reason may be due to the difference in the load distribution. The Westergaard theory relies on a semi-circular load distribution, while the finite-element program assumes a full circular load.

4. The ELSYM5 results give the lowest range of all theories used.

5. Any of the previously mentioned approaches describes fairly well the stress behavior due to different radii of bearing for the interior case. However, these approaches give low stresses for edge loading and more investigation may be necessary.

\subsection{LOAD-STRESS RELATIONSHIP}

\subsubsection{Interior Loading}

A direct comparison between the observed and computed stresses for the interior loading case for the 1 inch and 1.33 inch slabs are shown in Figures 4.3 and 4.4 , respectively. The observed stresses shown are the maximum critical values when the loads are applied at a considerable distance from any of the edges. These values were computed by Lall (1969) through strain measurement, made directly under the load in the radial and tangential directions using the following relations: 

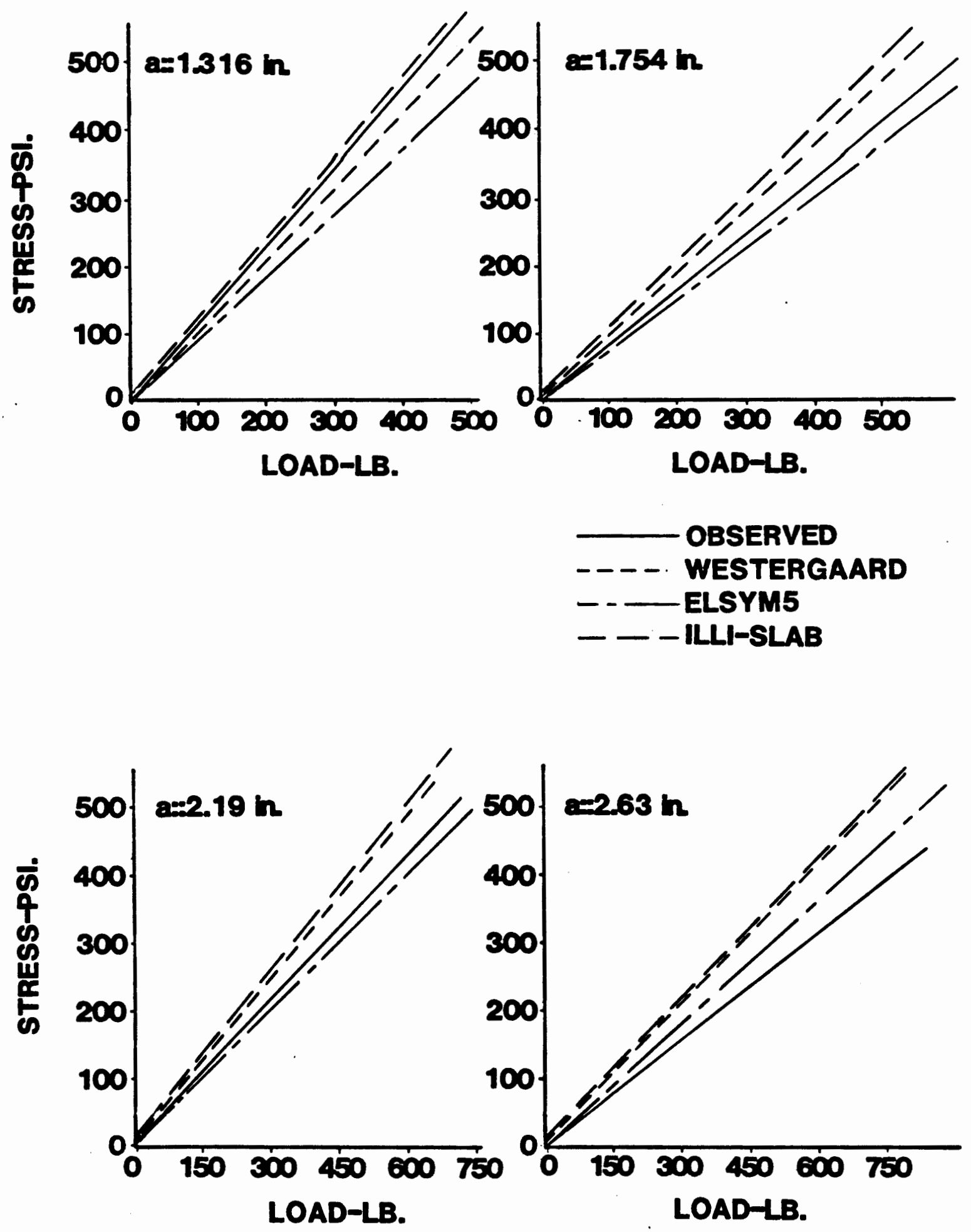

Figure 4.3 Load-stress relationship for the 1 in. slab interior Toad 

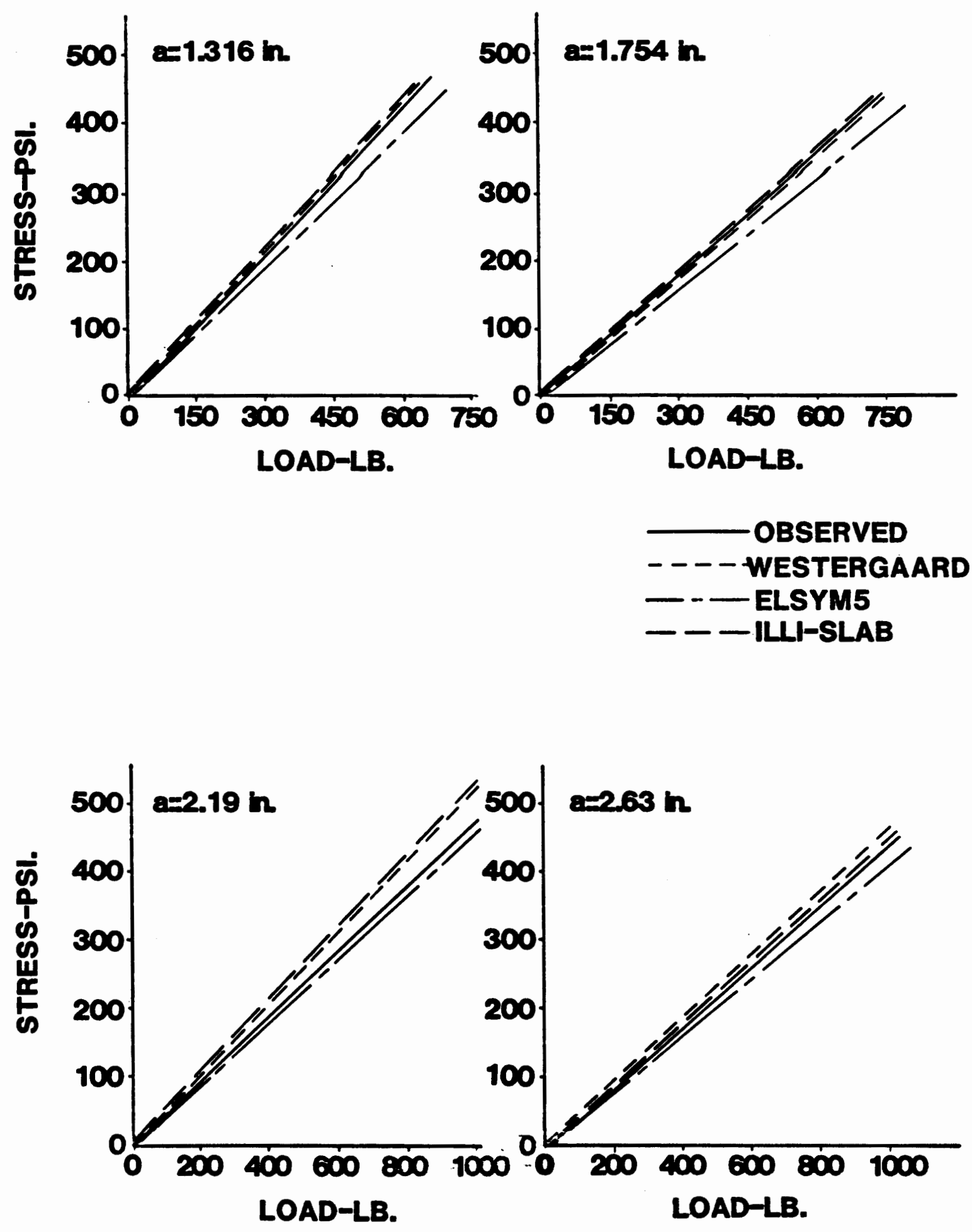

Figure 4.4 Load-stress relationship for the 1.33 in. slabinterior load 


$$
\begin{aligned}
& S_{x}=\frac{E}{1-m^{2}}\left(e_{x}+m e_{y}\right) \\
& S_{y}=\frac{E}{1-m^{2}}\left(e_{y}+m e_{x}\right)
\end{aligned}
$$

where $S_{x}$ and $S_{y}$ are stresses in the directions of the $x$-axis and the $y$-axis, respectively.

$e_{x}$ and $e_{y}$ are the strain measurements along the $x$-axis and the $y$-axis.

The theoretical stress values are based on Westergaard formula, ELSYM5, and ILLI-SLAB. From Figures 4.3 and 4.4 the following conclusions may be made.

1. The stress in the pavement slab is directly proportional to the applied load for a given contact area.

2. The ILLI-SLAB stress results either match the observed stresses or are slightly higher.

3. The elastic layer theory stresses are lower than the other theories. However, these results are consistent with the observed stresses and for all practical purposes are acceptable.

4. The Westergaard formula gives stress results very comparable to the observed ones for all cases, except where the radius of bearing area is 2.63 inches, and the pavement thickness is 1.33 inches. For this case all theoretical stresses are higher.

From the previous observations, it could be stated that when the loads are applied at the interior of the slab the observed and 
theoretical stresses are close and any of the above theories would represent the stress behavior in this region.

\subsubsection{Edge Loading}

Figures 4.5 and 4.6 present the load-stress relations for the 1 inch and 1.33 inch slabs, respectively, when the load is applied at the edge of the slab at a distance from any corner. The figures show a direct comparison between observed and theoretical streses. The theoretical stresses are based on Westergaard formula and the finiteelement program. The observed stresses seem much higher than either theory. The loss of the subgrade support due to the differential moisture warping of the slabs reported by Lall (1969) and Lall and Lees (1983) may be the main reason for this big difference. Another reason could be due to the following.

The Westergaard analysis (1926) for the edge loading case assumes that the loads are applied on a semi-circular area with the center at the edge. Lall's (1969) work, on the other hand, is based on a circular bearing area of radius equal to that suggested by Westergaard, and the circumference touching the edge of the slab. The strain gauges used were located at the center of the smallest and largest contact areas used and parallel to the edge. This difference in the bearing area and the locations of the center of that area may have been responsible for the stress variation.

Similarly, for the ILLI-SLAB program a square plate of bearing - area equal to that used is assumed, but one edge of the plate coincides with the edge of the pavement. This different load distribution may have given different stress results. 

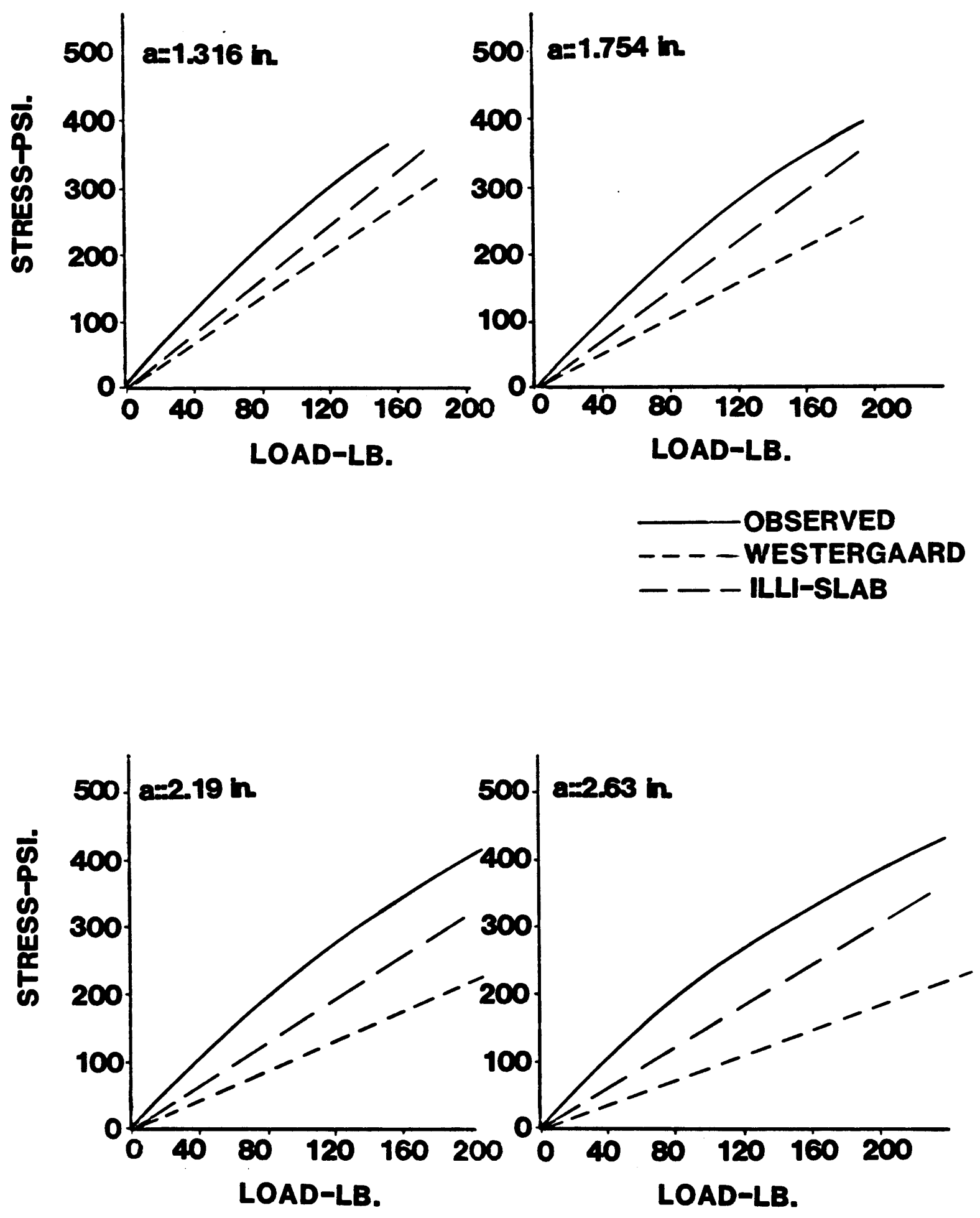

$\frac{\text { Figure } 4.5}{\text { edge load }}$ Load-stress relationship for the 1 in. slab- 

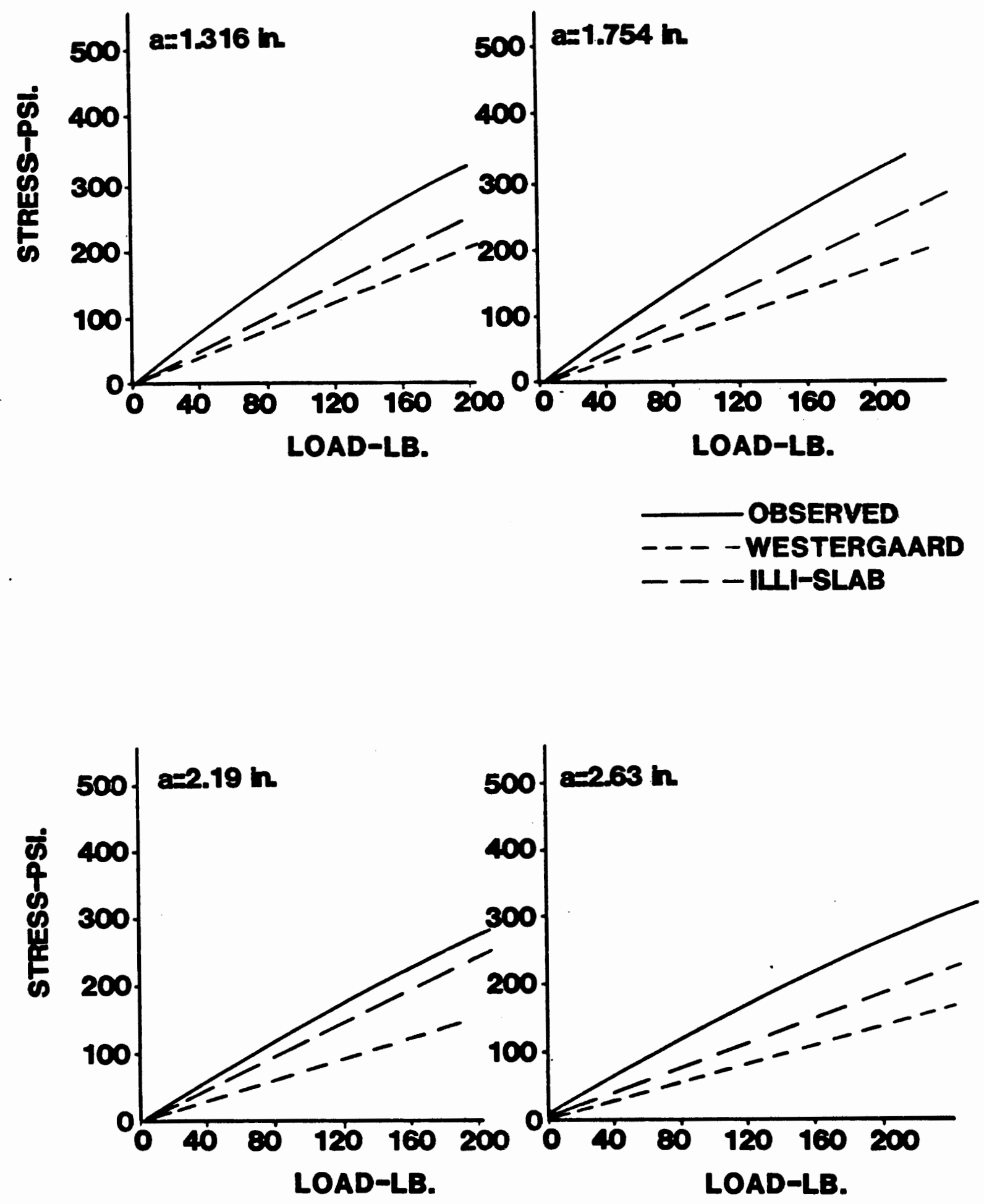

Figure 4.6 Load-stress relationship for the 1.33 in. slab edge load 
To accommodate for this difference in the radius of bearing area when a full circular plate is used for loading at the edge case, Vaswani and Krishna (1967) introduced a modified Westergaard equation based on observations given by:

$$
S_{e}=\frac{6.25 p^{0.8}}{h^{2}}\left[4 \log \frac{l}{b}+\log b-0.8\right]
$$

This equation is not used for comparison in this study, because many other modifications for Westergaard formula have been attempted. Most of these modifications give satisfactory results for the specific situation and not to all rigid pavements. Moreover, this equation exaggerates the shape of the observed curvatures shown in the figures.

Based on this analysis of the single slab laying direclty on the subgrade it may be concluded that, within the limits of investigation presented, the actual behavior of the pavement could be described fairly accurately by any of the methods discussed earlier, when the pavement is loaded at the interior. On the other hand, when a circular load is applied at the edge of the pavement, the conventional methods seem to give low stress values and caution must be exercised in evaluating these stresses. 


\section{CHAPTER V}

\section{STRESSES IN TWO-LAYERED SYSTEMS}

\subsection{GENERAL}

The design of overlays for existing pavements has presented a formidable task for engineers. Many unpredictable parameters control the interaction between overlay, base pavement and subgrade, including warping of the slab and continuity at both interfaces. In discussing Ithe analysis of a single slab placed directly on the subgrade warping and break of continuity are assumed to may have occurred. For the two layered-system the problem becomes more complex and most of the existing design procedures are empirical. These procedures are modifications of the design methods for determining the thickness of the overlay required as if a single slab were used. The design of concrete pavement overlay over concrete pavement is no different. The determination of this overlay thickness is arrived at by using the Portland Cement Association (PCA, 1965) procedure and is independent of the overlay design. This procedure may be fairly sound for well bonded overlays, where both the overlay and underlay are theoretically replaced by a single slab of same load-carrying capacity, assuming a continuity in stress at the interface. However, when speaking of partially bonded and unbonded overlays the equivalent thickness method is no longer correct and equations 2.13 and 2.14 given earlier are 
assumed to yield overlay thicknesses that are conservative. In addition, this method does not design for critical stresses in the underlay, which may control especially in situations where the modulus of rupture of the base pavement is low compared to the overlay.

In the following pages a comparison is made between the observed and computed stresses in the overlay for an unbonded system. Again, the experimental results are based on Lall's (1969) research while the theoretical stresses are mainly based on the ILLI-SLAB program. The Portland Cement Association design method is also included. The results are taken for $(1 / 1)$ and (1/1.33) overlay systems, where the number in the numerator represents the thickness of the overlay, in inches; and the denominator describes the thickness of the existing slab, in inches.

\subsection{INTERIOR LOADING}

Figures 5.1 and 5.2 present the load-stress relationship for (1/1) and (1/1.33) overlay systems, respectively, when the load is applied at the interior. For each radius of contact of the bearing area four curves are shown and are denoted by "OBSERVED", "PCA", "ILLI-SLAB", and "ILLI-SLAB(1)". The "OBSERVED" stress curve is based on Lall's (1969) work. The "PCA" curve is based on the Portland Cement Association method of equivalent thickness design. The stress values for this curve are derived as follows.

Consider the $(1 / 1)$ overlay system in Figure 5.1 . This sytems is represented by an equivalent single layer of thickness, $h_{e}$, which equals 

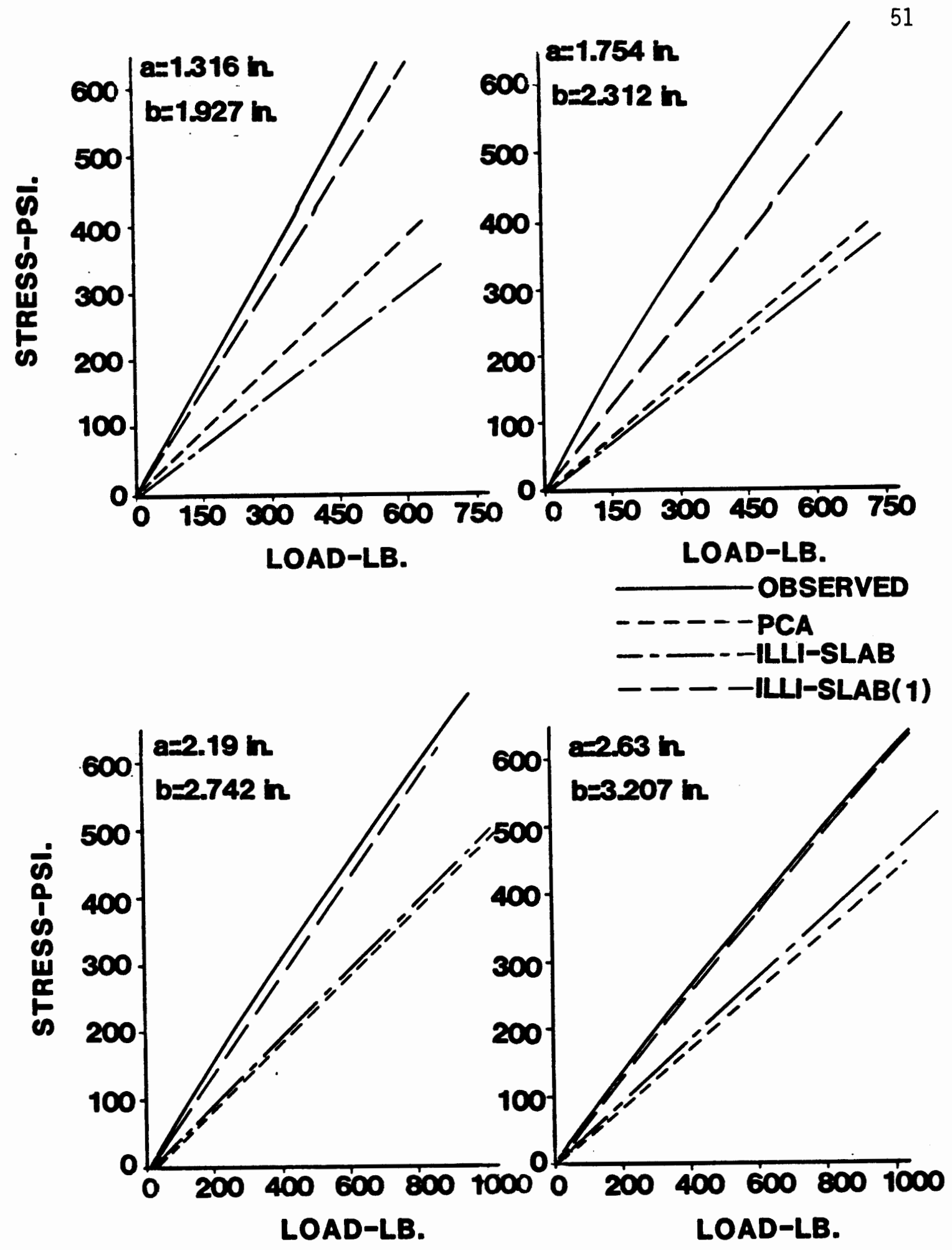

Figure 5.1 Load-stress relationship for (1/1) overlay interior Toad 


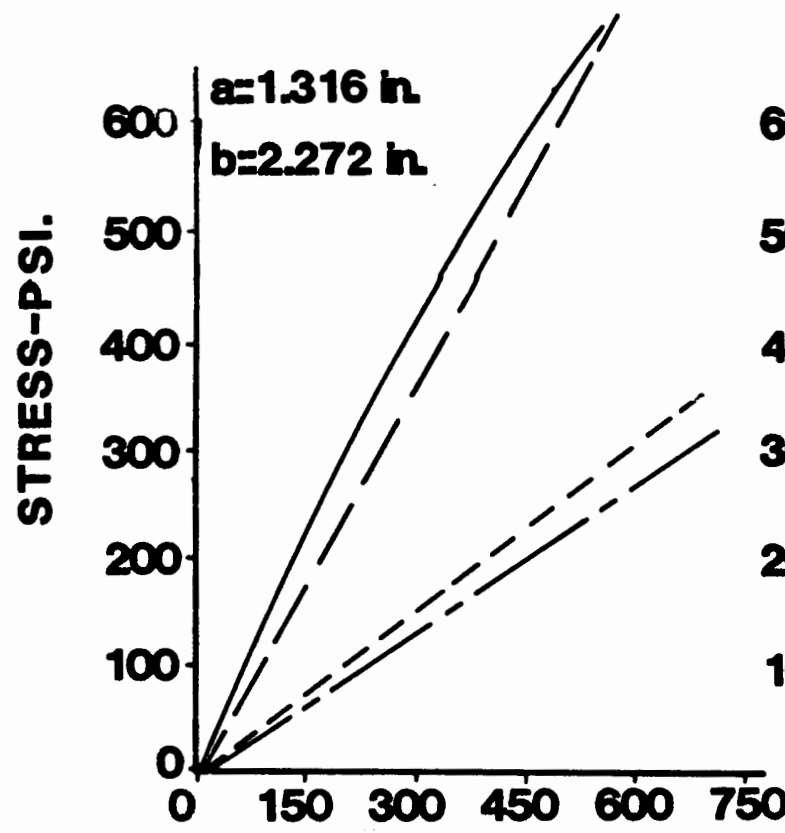

LOAD-LB.

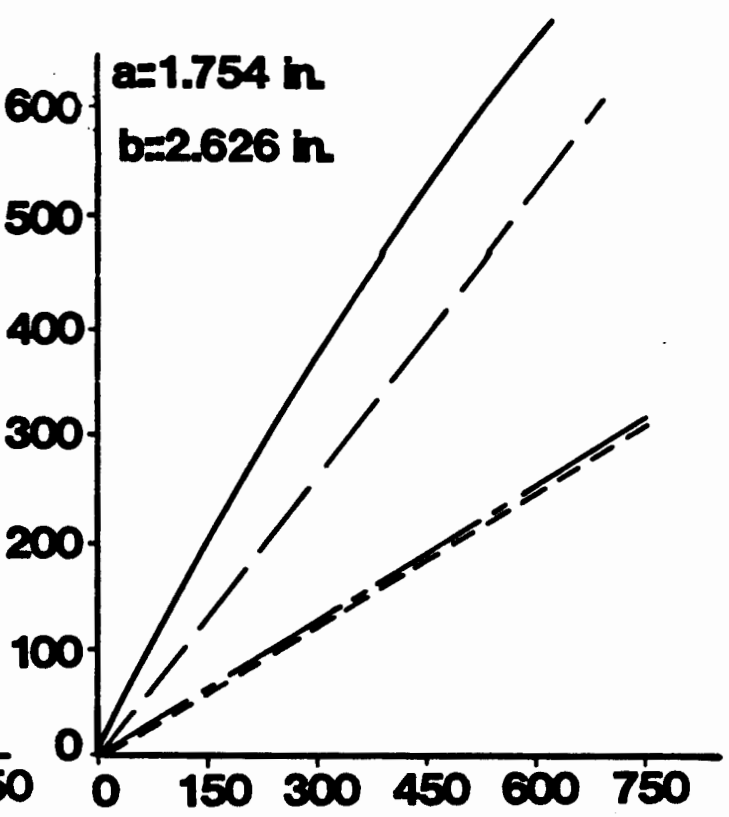

LOAD-LB.
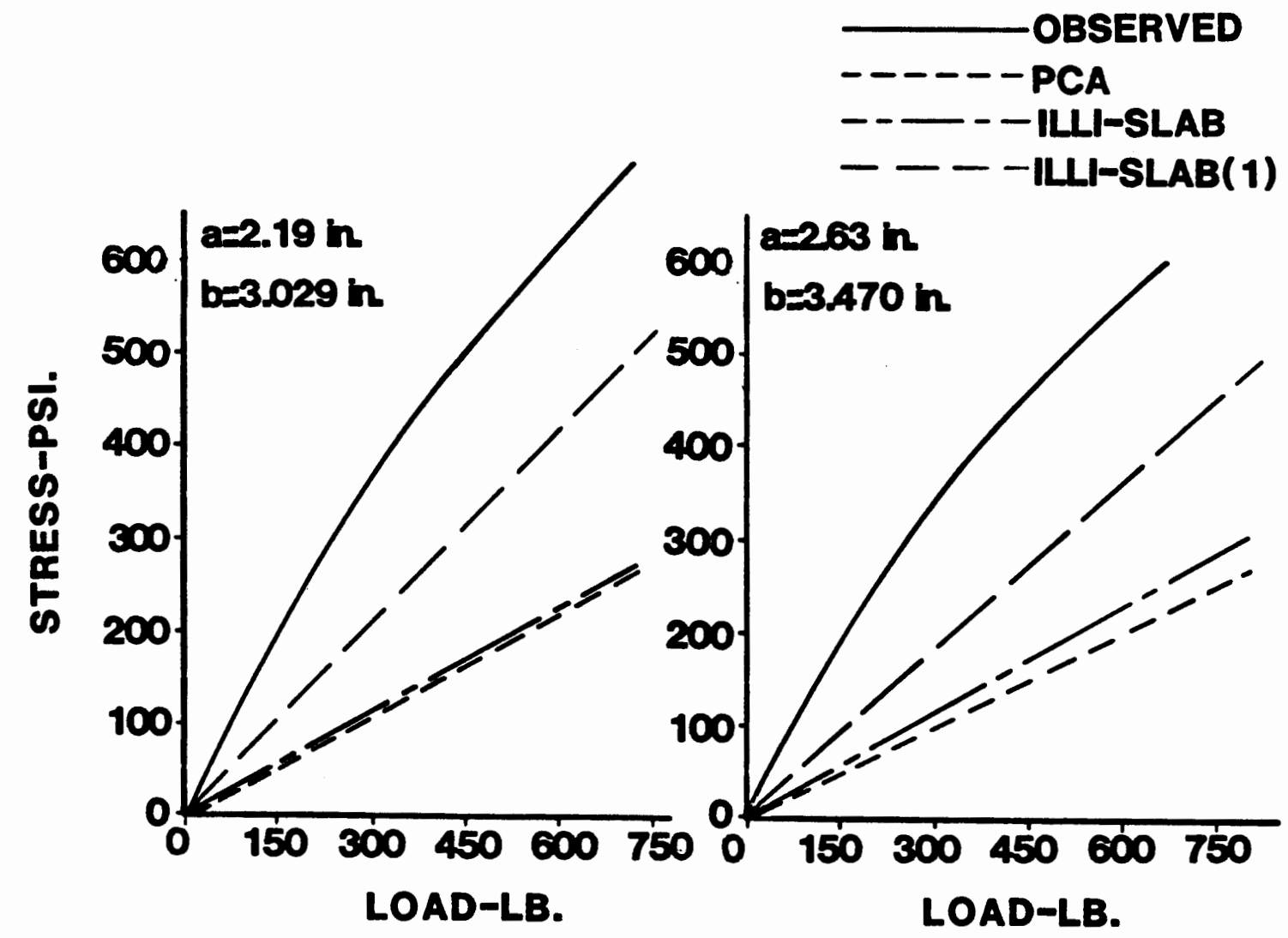

Figure 5.2 Load-stress relationship for (1/1.33) overlay interior Toad 


$$
\begin{aligned}
& h_{e}=\sqrt{h^{2}+h_{o}{ }^{2}} \\
& h_{e}=1.414 \text { inches }
\end{aligned}
$$

The critical stress for this imaginary single slab, when loaded at the interior, is given by equation 2.6 and repeated here for convenience

$$
S_{i}=\frac{0.316 P}{h^{2}}\left[4 \log \frac{\ell}{b}+1.069\right]
$$

Using properties of concrete and subgrade as before, the radius of relative stiffness, $\ell$, is then calculated as 6.695 inches. The corresponding stress equation becomes

$$
S_{i}=0.158 P\left[4 \log \frac{6.695}{b}+1.069\right]
$$

For any value of the radius of bearing, a, the linear load-stress relationship may be drawn.

The "ILLI-SLAB" curve is again derived from the ILLI-SLAB model with the same theoretical horizontal dimensions and square plate as used in the single layer placed on the subgrade. Stress computations are based on the assumption that no shear occurs at the interface between the slabs. This is considered equivalent to the unbonded overlay system constructed by Lall (1969). Bondage is reduced in the model by using an "M.G.A." pad which acted as a "slip layer" and is reported to be very effective.

As for the "ILLI-SLAB(1)" stress results shown, they are a 
modification of the load-stress relationship done by the author, and will be explained in detail later in this thesis.

From Figures 5.1 and 5.2 , it seems that the computed stress results are far below the observed ones, with the difference between theoretical and experimental values decreasing with the increase in the contact area. Computed stresses, on the other hand, seem very compatible and fairly close to each other. The figures also show that the critical stress decreases with the increase in the radius of bearing regardless of the approach used.

Comparing Figure 5.1 to 5.2 , it shows that the maximum stresses in the overlay for the (1/1.33) system are somewhat higher than the (1/1) overlay system for the same loading conditions. Part of this high stress in the thicker system may be attributed to the lack of support between the overlay and base pavement. This condition is confirmed by Lall (1969) in stating that the underlying slab for the (1/1.33) system did not experience any stress until an average load of 200 lbs. was exerted on the system. This observation indicates the possibility of existence of a gap between the two slabs and hence an upward warping of the overlay at the interior.

The other reason for the high stress in the (1/1.33) overlay may be due to the effect of load spreading characteristics of the system. This point needs further investigation and is discussed in detail as follows.

\subsection{STRESS BASED ON THE ORDINARY THEORY OF SLABS}

The reason for higher stresses in the (1/1.33) overlay than the 
(1/1) system, and in general high observed stresses in the overlay relative to the computed ones, may be best explained by Westergaard (1926) analogy of the special theory of slabs as opposed to the ordinary theory. But before this analogy is attempted a review of the basic common assumptions used in the derivation of Westergaard theory and the ILLI-SLAB model is recommended. Both theories rely on the following assumptions:

1. The concrete slab acts as a homogeneous, isotropic, elastic solid in equilibrium.

2. The reactions of the subgrade are vertical only and they are proportional to the deflection of the slab.

3. The small-deformation theory is used, with the assumption that a line normal to the middle surface in the undeformed slab remains straight and perpendicular to the neutral surface.

So, the analysis of pavement slabs is based on the ordinary theory for both approaches. This theory is found to give satisfactory results at all points except in the immediate neighborhood of a concentrated load, and leads to a satisfactory determination of the deflection at all points. For the concentrated load case Westergaard suggested to use the special theory of slabs.

\subsection{STRESS BASED ON THE SPECIAL THEORY OF SLABS FOR A SINGLE LAYER}

The derivation of the special theory of slabs rests on two assumptions: one is that Hooke's law applies; the other is that the 
material keeps its geometrical continuity at all points. The special theory of slabs, because of its complexity relative to the ordinary theory of slabs, is usually avoided except when dealing with the local effects around a concentrated load.

To make stress computations easier the results of the special theory are usually expressed in terms of the ordinary theory in the following manner: The tensile stress produced by a uniformly distributed load at the bottom of the slab and under the center of the loaded area is the critical stress. This is always true except when the radius of the loaded area is so small that some of the vertical stress near the top of the slab becomes more important. In this case one can still use the ordinary theory by assuming the load to be uniformly distributed over the area of the circle with the same center, but with a fictious radius, b. For a single concrete slab lying on the subgrade Westergaard used Equation 2.5 for the modification of the radius of bearing and is repeated here for clarification:

$$
b=\sqrt{1.6 a^{2}+h^{2}}-0.675 h
$$

This equation is based on numerical computations obtained by Nadai in 1928 (see Westergaard, 1926) and is found to give satisfactory results especially when a concentrated load is concerned.

Since the ILLI-SLAB program and Westergaard equations are derived with the same basic assumptions, it may be concluded that the equivalent radius of bearing based on the special theory of slabs, is 
applicable to the ILLI-SLAB program as well. To further demonstrate the validity of this conclusion a concentrated load of $p=600$ lbs. is assumed to act at the interior of a 4.05 inch thick concrete slab. Based on the special theory of slabs, the equivalent radius is calculated using Equation 2.5 and found as 1.316 inch. The horizontal dimensions of the slabs and properties of the concrete and the subgrade are assumed to have the same values as Lall's model ( $E=6.75 \times 10^{6}$ $\left.\mathrm{lb} / \mathrm{in}^{2}, \mathrm{~m}=0.15, \mathrm{~K}=810.0 \mathrm{lb} / \mathrm{in}^{2} / \mathrm{in}\right)$. This information gives stress values of $60.87 \mathrm{lb} / \mathrm{in}^{2}$ and $59.996 \mathrm{lb} / \mathrm{in}^{2}$ whether using Westergaard's equation or the finite-element model, respectively.

The application of the equivalent radius of bearing for the edge loading case cannot be properly checked for a concentrated load because the center of pressure for the equivalent circular load used by Westergaard is different from the rectangular plate used by the ILLI-SLAB program. Besides, when dealing with the edge loading case for a single slab system it has been shown that the finite-element program gives high stress values compared to Westergaard. With this in mind stress values of $95.33 \mathrm{lb} / \mathrm{in}^{2}$ and $127.07 \mathrm{lb} / \mathrm{in}^{2}$ for Westergaard and ILLI-SLAB systems, respectively, are anticipated.

\subsection{STRESS BASED ON THE SPECIAL THEORY FOR A TWO LAYER SYSTEM}

For a bonded overlay system one could treat the whole system as a monolithic slab, and consider a concentrated load as if it were on a single layer laid directly on the subgrade. For the unbonded concrete pavement system the above relationship does not appear to hold true; 
perhaps due to the overlay-base pavement interaction. However, based on the same analogy for the single slab, one could assume a certain relationship to exist between the imaginary radius of bearing, $b$, the actual radius, a, and some combination of the overlay-underlay thicknesses. This relationship is estimated as:

$$
b=\sqrt{1.6 a^{2}+h^{2}}-0.3375 \alpha h
$$

where. $h$ is the total thickness of concrete slabs

$\alpha$ is the ratio of the overlay thickness, $h_{0}$, to that of the existing pavement, $h_{e}$.

Equation 5.1 is derived assuming that the overlay and underlay slabs have the same elastic properties. This equation is used in the ILLI-SLAB program in such a way that the actual radius of bearing is replaced by the equivalent radius carrying the same stress and has the same center of pressure.

Although the above equation is estimated so as to best fit the experimental results, two questions still come to mind. First, on what basis is this equation arrived at, and second, for what values of the radius of bearing area, a, does the ordinary theory apply.

As for the first question, the equivalent radius of bearing area is estimated based on the reasoning that the same hyperbolic relation, given by Equation 2.5, that applies to the one layer system may apply to the two layer system. The constant, $\alpha$, is introduced because it has been found that, for any constant loading conditions, the thinner the 
overlay gets with respect to the underlay, the larger the equivalent radius of bearing area has to be estimated. This may be attributed to the increased effect of the vertical stresses at the top of the overlay. For the range of contact radius values where the ordinary theory applies, one should keep in mind that for the one layer system, these values are derived theoretically by setting the equivalent radius of bearing, $b$, equal to the actual radius. This value was calculated as $1.724 \mathrm{~h}$. By the same reasoning the limits for Equation 5.1 where the ordinary theory applies is:

$$
a=h\left[1.125 \alpha / 2-\sqrt{\left.0.5062 \alpha^{2}-1.675\right]}\right.
$$

For values of $\alpha$ less than 1.82 the term under the square root is negative. This means that the value of the equivalent radius of bearing derived from equation 5.1 should be used instead of the actual radius. In other words, Equation 5.1, in this case, is always used in modifying the actual radius of bearing area, a. On the other hand, when $\alpha$ is greater or equal to 2.97 the ordinary theory applies and no modification is necessary. For the values of thickness ratio, $\alpha$, between 1.82 and 2.97 Equation 5.2 is used to find the limit necessary for the modification based on the special theory. For example, if the ratio of the thickness of the overlay to the underlay is 2.0 then, from Equation 5.2 the critical value of the radius of bearing, a, is 1.716 $\mathrm{h}$. This means that for the actual radius of bearing less than $1.716 \mathrm{~h}$ the special theory applies, and the equivalent radius is used. For other values of the radius of bearing area, the ordinary theory holds. 
Stress factor charts, for full friction at the interface, derived by Peattie and used by Yoder and Witczak (1975) show that the effect of the vertical stress decreases as the ratio of the thickness, $\alpha$, increases. For the case when the overlay and underlay have the same elastic properties with the modulus of elasticity much higher than the subgrade, then the effect of the vertical stresses may be neglected when $\alpha$ is greater than four. However, the theoretical values for the limits suggested by Equation 5.2 are used to assure continuity in the radius of bearing area between the ordinary and special theory.

\subsection{STRESS RESULTS BASED ON THE MODIFIED THEORY}

\subsubsection{Interior Loading}

Figures 5.1 and 5.2 presented earlier show the stress results based on the modified theory along with the curves defined earlier. The modified load-stress curve is denoted by ILLI-SLAB (1) since it is based on the analysis made using the finite-element program. This curve is derived on the same information used for the derivation of the ILLI-SLAB stress curve, except for the value in the radius of bearing area. This value is estimated from Equation 5.1 and its value is shown in the figure as b. On the same figure the actual value of the radius, a, is shown.

From Figure 5.1 one may state that the observed and ILLI-SLAB (1) stress results are very close and for all practical purposes equal. The figure also shows that the modified stress values decrease with the 
increase in the radius of bearing area; with the results approaching those of ILLI-SLAB. This last statement is confirmed in Figure 5.2 by showing the same behavior. The stress results from Figure 5.2, however, seem somewhat lower than the experimental results. But, if the upward warping at the interior of the overlay, which is reported earlier, is taken into consideration, one may say that the ILLI-SLAB (1) stress results are able to predict the behavior of the overlay system.

\subsubsection{Edge Loading}

Figures 5.3 and 5.4 show the load-stress relationship for the $(1 / 1)$ and (1/1.33) overlay systems. In these figures the observed stresses are compared with the "theoretical" ones. The theoretical stresses are again based on the PCA, ILLI-SLAB, and ILLI-SLAB (1). Hence, the derivation of these curves need not to be explained here, except in the calculation of the equivalent effective radius of bearing for the ILLI-SLAB (1).

The equivalent radius of bearing, b, calculated from Equation 5.1 has the same magnitude as calculated for the interior loading case. This equivalent radius is larger than the true radius, a. Therefore, when the concrete overlay is loaded at the edge, part of this equivalent circle lies outside the slab edge and considered ineffective as shown in Figure 5.5. The effective area would be that part of the equivalent circle that is located on the pavement itself and may be calculated from the geometry of the figure. 

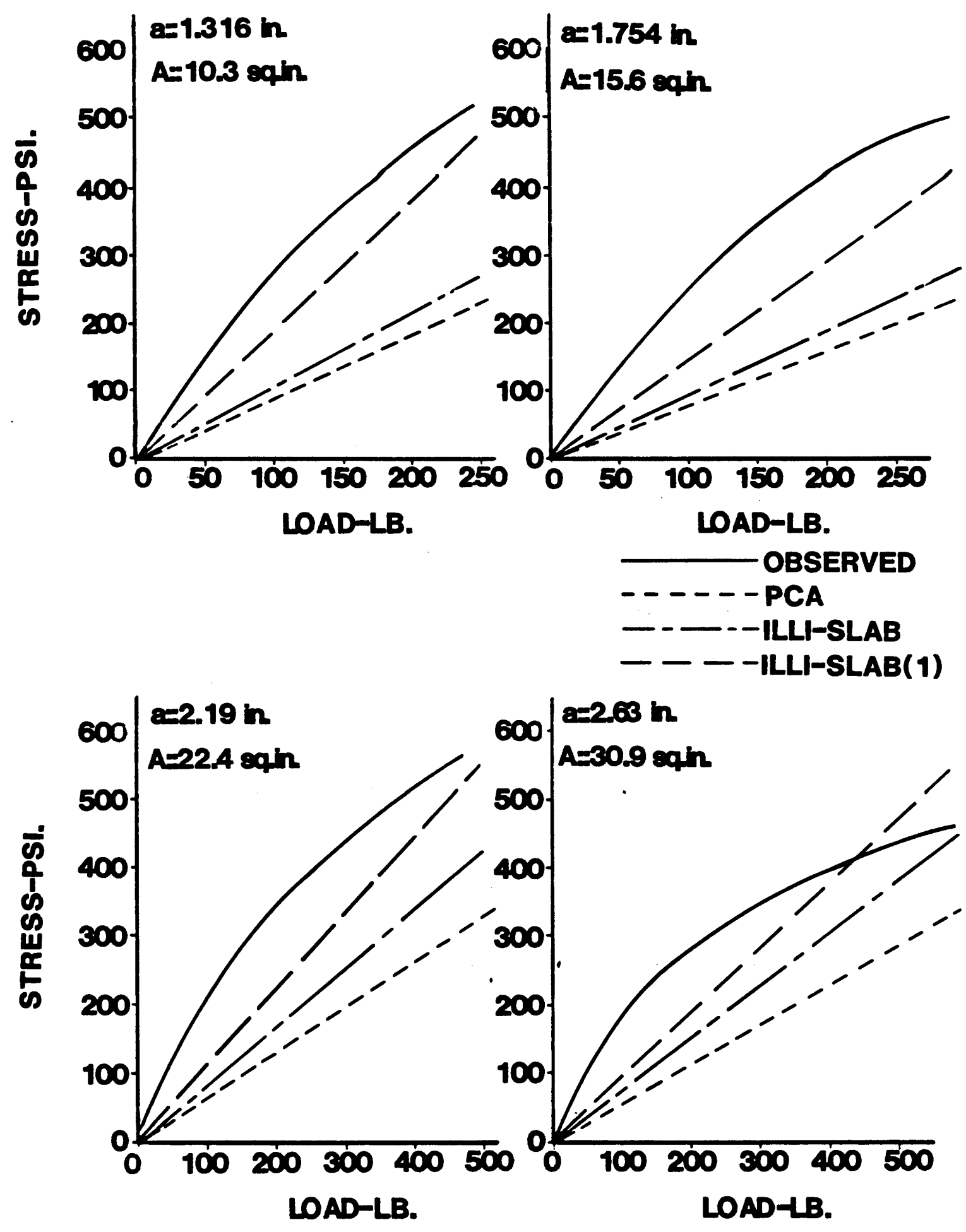

Figure 5.3 Load-stress relationship for (1/1) overlay edge load 

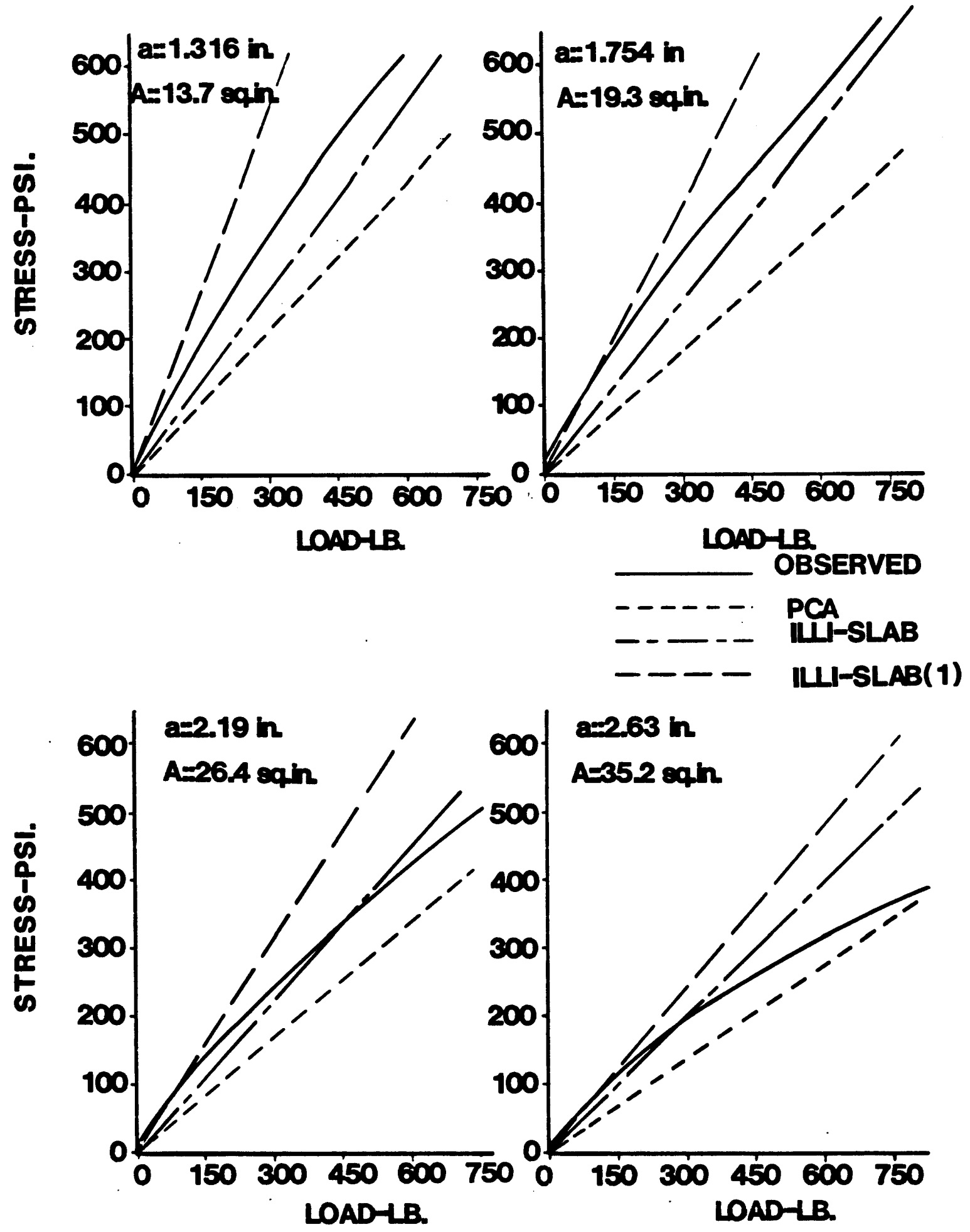

Figure 5.4 Load-stress relationship for (1/1.33) overlay edge Toad 


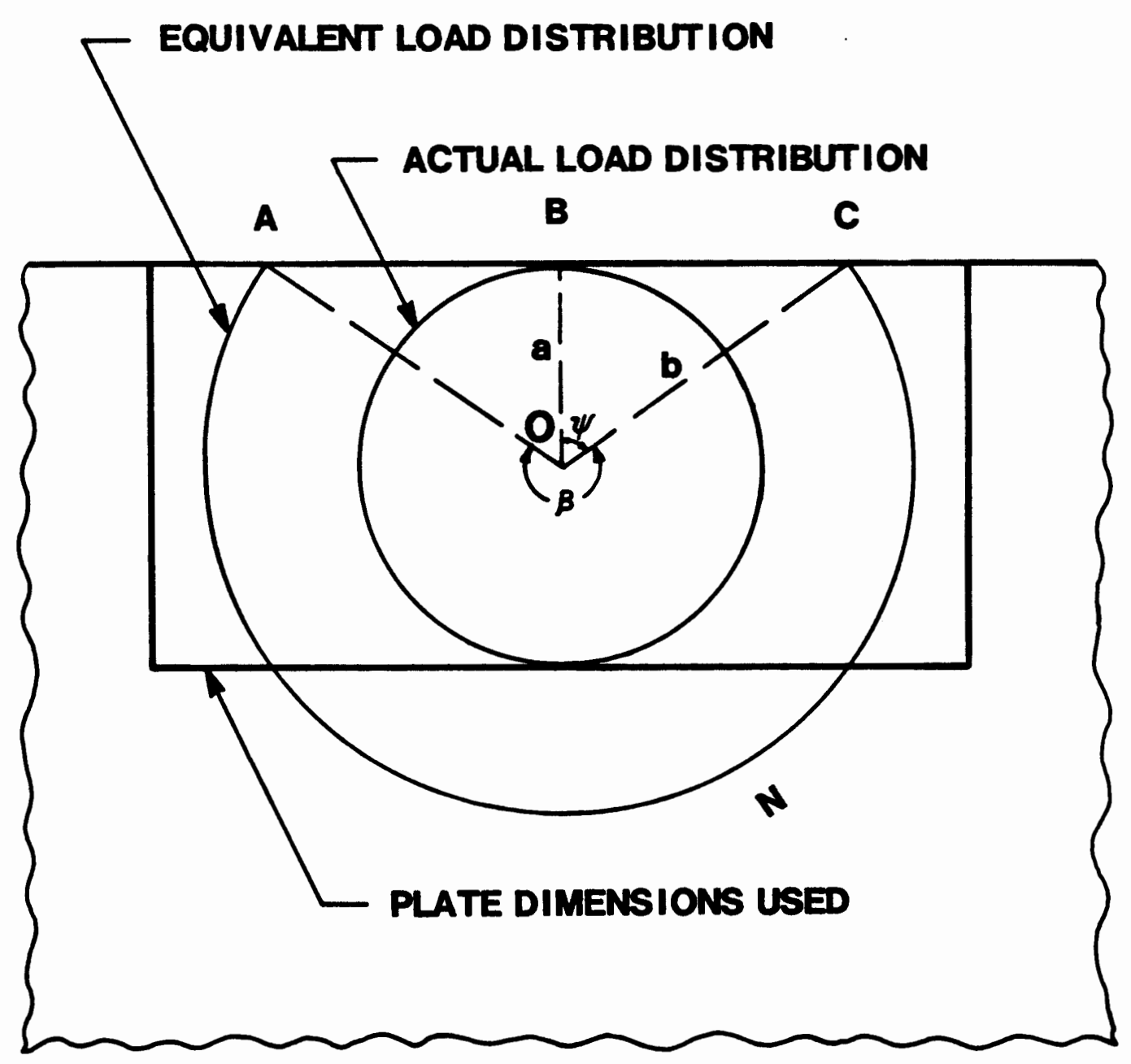
Figure 5.5
of an overlay system. 
Effective area $=$ area $(A O C N A)+\operatorname{area}(A O C B A)$

Effective area $=\pi b^{2} B / 360+a \sqrt{b^{2}-a^{2}}$

but $\beta=360-2 \Psi$

$\beta=360-2 \cos ^{-1}(a / b)$

Then, effective area $=\left[360-2 \cos ^{-1}(a / b)\right] \pi b^{2} / 360+a \sqrt{b^{2}-a^{2}}$

The numerical value of this effective area is denoted by, A, as shown in Figures 5.2 and 5.3. This new area is finally modified to a rectangular area to be used in the finite-element program. The area is located at the edge of the plate in such a way that the center of pressure of this area coincides with that of the original circular plate. That is, the centroid of this rectangular plate is located at a distance from the edge equal to the true radius of the bearing area.

With the dimensions of this plate calculated, the load-stress relationship for the ILLI-SLAB (1) is obtained as shown in Figures 5.3 and 5.4 From these figures the following conclusions may be made.

1. The maximum value of the stress decreases with the increase in the radius of bearing area. This statement seems valid whether observed or theoretical stresses are concerned.

2. The stress results based on the Portland Cement Association (PCA) method seem to give the lowest range of values of the critical stresses. This may be due to the actual distribution of the load. The load used was a circular plate, while the PCA method of stress computations is based on a semi-circular load distribution as suggested by Westergaard (1926). 
3. As expected, the ILLI-SLAB stress values are generally low compared to the experimental ones; and the equivalent load distribution procedure is recommended.

4. In spite of the fact that the ILLI-SLAB (1) stresses seem somewhat lower for the (1/1) system, and higher for the (1/1.33) system, when compared to the actual stresses, they seem to give a better prediction of the boserved stress behavior. As a matter of fact, the explanation for the stress differential can be sought in Lall's (1969) observation of the upward and downward warpings of the $(1 / 1)$ and (1/1.33) overlay systems, respectively. Due to the upward edge warping of the (1/1) overlay system, a gap is reported to exist between the overlay and base pavement. This in return would increase the observed stress in the overlay because of the lack of support.

Similarly, the downward warping at the edge of the (1/1.33) overlay may have received full, or more than full support, causing lower observed stresses. The downward warping of the $(1 / 1.33)$ system will create a gap between the layers at the interior. This gap, in return, will cause a high observed stress due to the loss of contact between the overlay and underlay. Figure 5.2 as reported earlier, shows that the observed stresses for the (1/1.33) overlay system, when loaded at the interior, is actually higher than predicted.

\subsection{EFFECT OF THE RADIUS OF BEARING AREA}

To better understand the behavior of an overlay system, its stress 
variation in terms of the radius of bearing should be analyzed. This stress behavior is shown in Figures 5.6 and 5.7. The figures deal with the interior and edge loading cases, respectively. The applied loads are assumed constant and equal to $600 \mathrm{lb}$. for the interior loading case, and $300 \mathrm{lb}$. for the edge case. Each loading case is divided into two parts, (A) and (B) for the (1/1) and (1/1.33) overlay systems, respectively. For each overlay system three curves are shown. The depicting observed stresses and those computed by the finite-element model and are denoted by ILLI-SLAB and ILLI-SLAB (1).

From Figure 5.6 the following conclusions may be made:

1. The stress reduction with the increase in the radius of bearing area, based on ILLI-SLAB is very slight and linear. The stress variation is less than $15 \%$ when the radius of bearing area is doubled.

2. The stress results of the ILLI-SLAB are very low compared to the observed ones.

3. In general terms, it could be stated that the stress decreases with the increase in the radius of the bearing area.

4. The ILLI-SLAB (1) stress results describe more accurately the behavior of the stresses in the overlay than the ILLI-SLAB model.

5. The ILLI-SLAB (1) stresses have the same trend as the observed ones and seem compatible.

6. The ILLI-SLAB (1) curve approaches that of the ILLI-SLAB with the increase in the radius of bearing. That is, the ILLI-SLAB results are asymptotic with the ILLI-SLAB (1). 

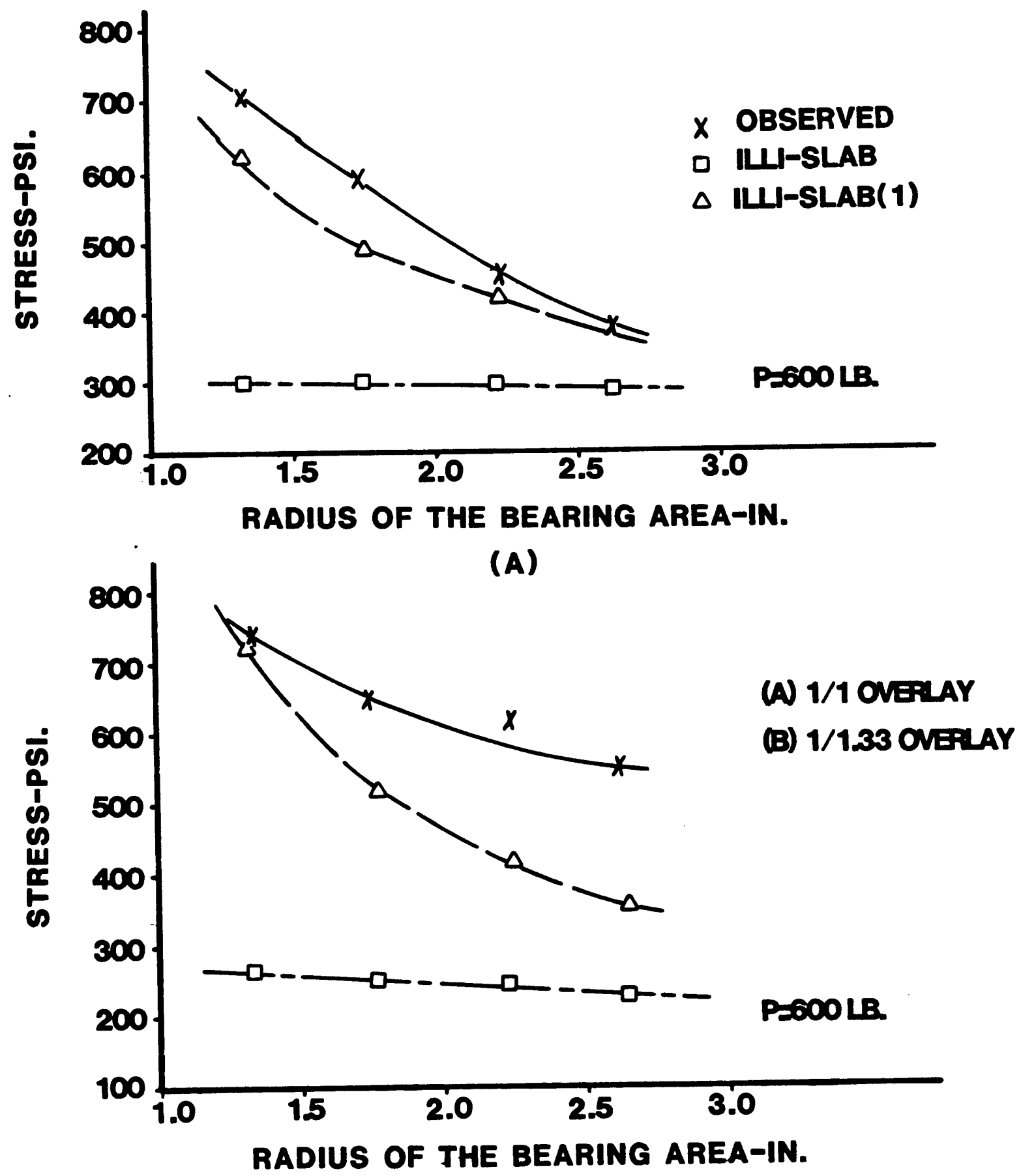

(B)

Figure 5.6 Stress versus radius of bearing - interior load 


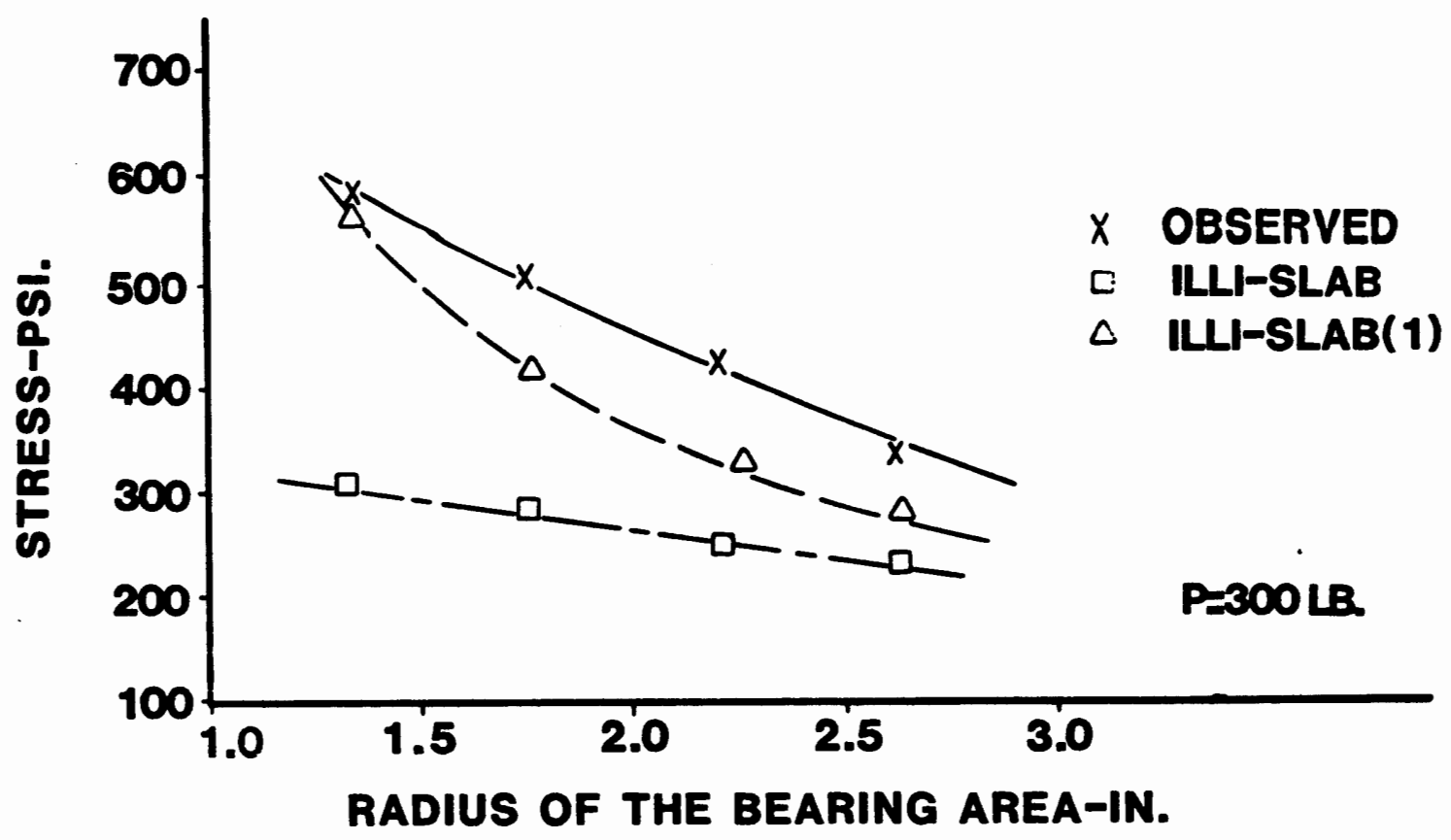

(A)

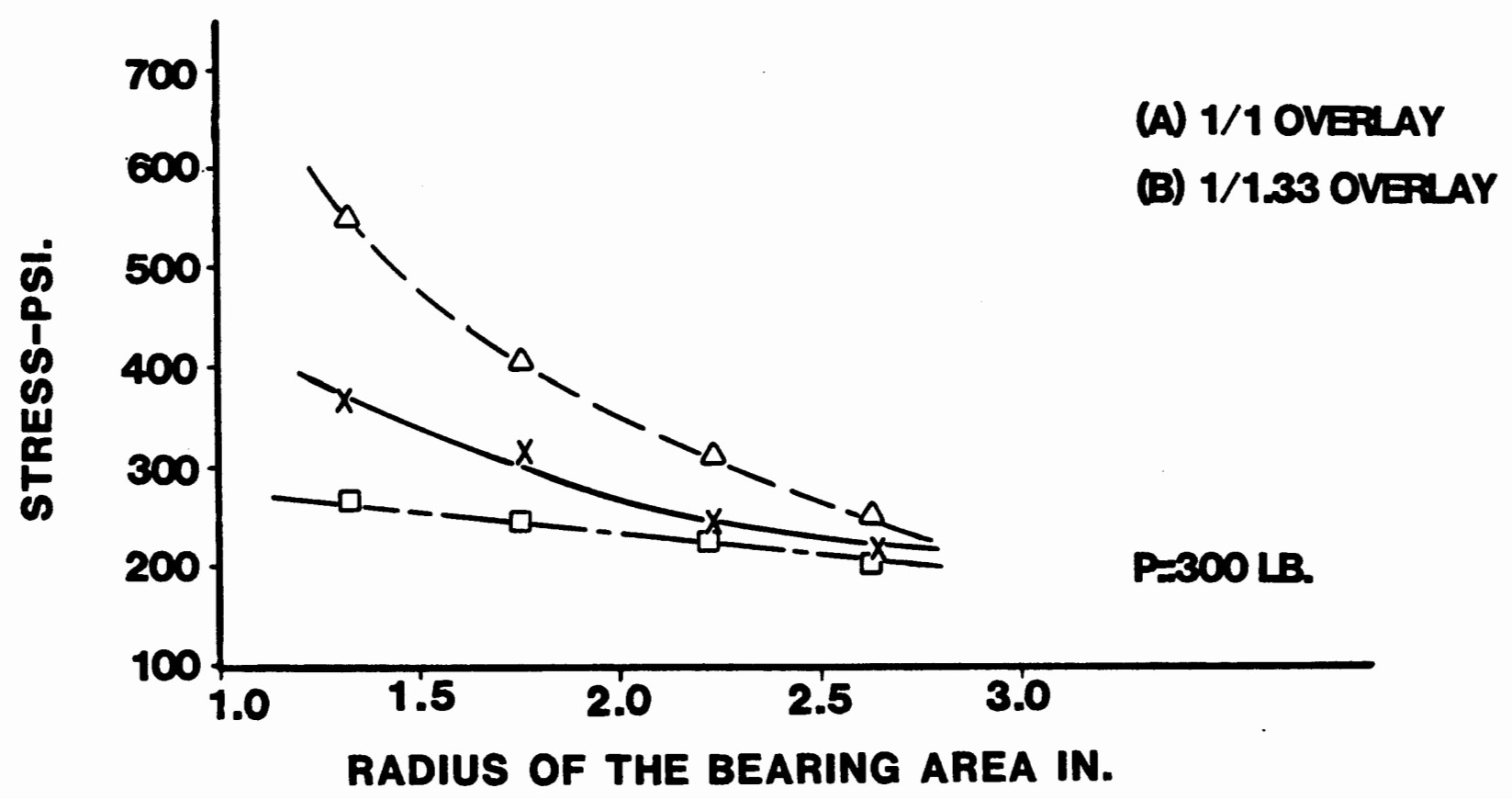

(B)

Figure 5.7 Stress versus radius of bearing = edge load 
As for Figure 5.7 the same conclusions made from Figure 5.6 apply with two modifications: The stress variations based on the ILLI-SLAB results are linear but not as minimal as the interior loading case; and it could be clearly stated that the ILLI-SLAB curve is asymptotic with both the ILLI-SLAB (1) and observed stresses.

One important note may be made when comparing the interior and the edge curvatures for the same overlay. A close examination of the observed and ILLI-SLAB (1) curves for the (1/1.33) overlay for example, shows that the average behavior of the observed stresses is very compatible with the modified theoretical stresses. That is, when the difference between the computed and observed stresses is high for a loading case, say the edge loading case of the (1/1.33) system, then this difference is low for the other case, which would be the interior loading case of the $(1 / 1.33)$ overlay system in this example. This difference, as mentioned earlier, is attributed to the warping effect.

\subsection{COMPARISON OF THE SPECIAL THEORY WITH THE PORTLAND CEMENT ASSOCIATION}

The stress results based on the Portland Cement Association method are shown in Figures 5.1 and 5.2 for the interior loading case, and Figures 5.4 and 5.5 for the edge loading case, respectively. From these figures it seems that these stresses are much below the observed stresses and by no means conservative. This low stress may be due to the ratio of the thickness of the overlay and the base pavement, $\alpha$, between the model used and actual field pavements. Mellinger (1963) describes the unbonded overlay design as: 
"A nonbonded design requires a greater thickness of overlay (than the bonded) and generally is used when the existing pavement is relatively thin in comparison with the thickness of the overlay, or when the base pavement contains numerous cracks."

This statement implies that the overlay thickness is, at least, twice as much as the base pavement, when the later has the same properties. Consequently, the effect of the equivalent radius of bearing may be neglected. To further explore this point, consider an example of a 1.36 inch overlay laid over a base pavement of 0.64 inches thick, and assume that both slabs and the subgrade have the same properties as the model used by Lall (1969). Moreover, assume that a load of $300 \mathrm{lb}$. is applied at the interior with a radius of bearing area, a, of 1.26 inches. The load, radius of bearing area, and the concrete overlay and underlay thicknesses are all dimensions of a model for the problem of designing the concrete overlay for the Air Force facility in Southern California, at Palmdale (Vallerga and McCullough 1969). The feasibility study based on the Corps of Engineers design method suggested the use of a 19 inch overlay over a 12 inch thick concrete pavement. Due to the structural conditions of the underlay of coefficient, $C$, of 0.75 is used. These thickness values of the overlay and underlay would give an equivalent thickness of 21.6 inches based on Equation 2.13. The maximum design loading of $1,000,000$ lbs. for a B-2070 jumbo jet of which a truck tire load of 59375 lbs. and pressure of $228.0 \mathrm{lbs} / \mathrm{in}^{2}$ are specified.

The modulus of the subgrade reaction, modulus of elasticity, Poisson's ratio, and the total thickness of concrete overlay-underlay 
system of 2 inches are assumed as given, so as to simplify the selection of the involved parameters between the model and the prototype, and to be able to compare the results with the (1/1) overlay system. The selection of the radius of bearing, and the load value are computed as suggested by Lall (1969) under the following equations

$$
a_{m}=a\left(h_{m} / h\right)^{3 / 4}
$$

and

$$
P_{m}=P\left(h_{m} / h\right)^{2}
$$

where the subscript $m$ refers to the model, and quantities with no subscript refer to the prototype.

With all of the above parameters computed the maximum critical stress based on the Portland Cement Association is then computed as 175 $\mathrm{lb} / \mathrm{in}^{2}$. When the load is applied at the interior of the $(1.36 / 0.64)$ overlay system.

The ILLI-SLAB (1) approach depends mainly on the equivalent radius of the bearing area. The value of the limit above which the radius of bearing does not need modification is calculated from Equation 5.2 as 0.827 inches, for the total thickness of 2 inches. Since the actual magnitude of the radius of bearing used is 1.26 inches which is higher than the limit value, no modification is necessary, and a radius of 1.26 inches is used. The stress calculation based on the ILLI-SLAB is then $164 \mathrm{lb} / \mathrm{in}^{2}$. This shows that the Portland Cement Association design method does give good results when the overlay is thick compared to that of the underlay. Otherwise, modification is necessary. 


\subsection{COMPARISON OF THE SPECIAL THEORY WITH CHILDS RESULTS}

The verification of the equivalent radius of the bearing area suggested in this thesis, with other experiments is fairly difficult due to the lack of experimental stress values for the unbonded concrete overlay systems. The only available data found is through the comparison of strain results obtained by Childs (1963, 1967). These strains are converted into stress values by the author using Equation 4.1 , and based on the assumption that the maximum strain, reported by Childs, is the same along the longitudinal and transverse directions. This assumption is considered valid for the interior loading case. Hence, stress comparison is considered only for the interior loading case, performed by Childs.

The test was conducted on a 3 inch concrete slab built on a 6 inch cement-treated subbase. The interlayer treatment was a 4-mil polyethylene film to prevent bond. The average modulus of elasticity of concrete slabs and cement-treated subbases were found to be $5.7 \times$ $10^{6} \mathrm{lb} / \mathrm{in}^{2}$ and $1.6 \times 10^{6} \mathrm{lb} / \mathrm{in}^{2}$, respectively. Poisson's ratio of the concrete slab and cement-treated subbases were assumed to be 0.15 and 0.25 , respectively. An average value of $82 \mathrm{lb} / \mathrm{in}^{2}$ is assumed for the subgrade. Load on the slab was applied through a 16 inch diameter plate. The maximum critical strain obtained for this system was $83 \times$ $10^{6}$ for a 9-kips load located at the interior. This strain is

equivalent to a stress of $556.6 \mathrm{lb} / \mathrm{in}^{2}$ based on Equation 4.1.

For the stress computations based on the ILLI-SLAB programs the loads are assumed to apply over a 14.2 inch square plate that having the same area as the 16 inch diameter plate. The maximum critical 
stress is then found to be $331.3 \mathrm{lb} / \mathrm{in}^{2}$.

To verify the equivalent radius of bearing area suggested, it is first necessary to convert the cement-treated cement into an equivalent concrete underlay with the same properties as the overlay. This is accomplished on the basis of the flexural stiffness method (Ullidtz and Peattie, 1980). This method states that if two layers of moduli, $E_{1}$ and $E_{2}$, and thicknesses, $h_{1}$ and $h_{2}$, respectively, are to have the same flexural stiffness then

$$
\frac{E_{1} h_{1}^{3}}{1-m_{1}^{2}}=\frac{E_{2} h_{2}^{3}}{1-m_{2}^{2}}
$$

The equivalent thickness of the cement-treated subbase is found to be 3.98 inches. This means that the 6 inch cement-treated subbase, may be theoretically replaced by a 3.98 inch concrete overlay with properties the same as the overlay. The ratio of the overlay to underlay is then calculated as $\alpha=0.754$, and the equivalent radius of bearing, based on Equation 5.1, is $b=10.52$ inches. This equivalent radius corresponds to a square plate of edge 18.64 inches. The stress value for this radius is calculated by using the finite-element model as $523.63 \mathrm{lb} / \mathrm{in}^{2}$. Note that equivalent thickness method is used only for the calculation of the equivalent radius of the bearing area. The properties of the cement-treated subbase are used as is in the finite-element program.

This comparison shows that, based on the equivalent radius of the bearing area, stress results check closely with the available 
experimental results, and should be used, especially when the ratio of the thicknesses of the overlay to the underlay is less than two.

\subsection{STRESS IN THE UNDERLAY}

In this analysis of the concrete overlay systems stresses in the underlay have not been considered so $f a r$. This is not to say that these stresses are not important. In fact, in some cases, stresses in the underlay slab may control the design if their value is higher than the allowable stresses in the base pavement. In this research, however, since both the overlay and underlay slabs have the same properties including the modulus of rupture; and since stresses in the underlay pavement are less than the overlay, these stresses have not been analyzed in this thesis and their effect on the design is considered secondary.

One comment about the stresses in the underlay slab that is worth mentioning is that the observed stresses in these slabs are less than predicted by the theory, whether the load is applied at the interior or the edge. These results are not shown here and may be obtained from Lall's (1969) work and the finite-element solutions. The reason for this higher theoretical stress may be attributed to the overlay-underlay interaction. Because of the effect of load. distribution on the system, the increase in the stress value in the overlay is accompanied by a decrease in the underlay. In other words, the increase in the equivalent radius of the bearing area on the overlay may contribute to a decrease in the effective radius of bearing on the underlay. 
CHAPTER VI

\section{CONCLUSION AND RECOMMENDATIONS}

The design procedures for concrete pavements and concrete overlays spring primarily from the theories developed by Westergaard and Burmister. Some of these design approaches are based on the empirical modification of the original theories, others are mere simplifications. The main objective of this study has focussed on comparing the experimental stresses in concrete pavements and unbonded overlays with some of the available procedures. However, before this comparison is made, the effect in the variation of the properties of material on the computation of stresses is analyzed. The results of this investigation may be summarized as follows.

\subsection{VARIATION IN THE PROPERTIES OF THE MATERIALS}

1. The percentage of error in stress computations based on the ELSYM5 is higher than Westergaard's equation. This leads to the conclusion that the theory used for predicting stresses in the pavement plays an important role in estimating the percentage error expected due to the variation in the material property.

2. The trend in the stress variation, due to the change in magnitude in the involved parameters, whether using the elasticlayered theory or the Winkler foundation model is the same. 
3. An average value of 0.5 for the Poisson ratio of the subgrade seems reasonable, since minor variation in this ratio hardly offset the stress values.

4. Reliance on the safety factor is better understood in terms of the variation in the properties of the material used.

\subsection{SINGLE SLAB ON SUBGRADE}

\subsubsection{Interior Loading}

1. For a given load the magnitude of the stress in the slab decreases with the increase in the area of contact regardless of the approach used.

2. For a given radius of bearing area, the maximum tensile stress is directly proportional to the applied load.

3. The computed stresses when considering the foundation as an elastic medium are lower than those obtained by Westergaard, or the finite-element model, and in general less than the observed stresses.

4. Good agreement is achieved between the observed stresses and those obtained by Westergaard and the ILLI-SLAB methods.

\section{$\underline{6.2 .2 \text { Edge Loading }}$}

1. The maximum critical stress in the concrete slab decreases with the increase in the radius of bearing area for a given load. 
2. The maximum observed stresses are higher than predicted by theory; this difference is most likely due to warping of the slab.

3. Stresses based on the finite-element model are higher than those obtained by Westergaard's method. The cause may be due to the way the load is distributed through the slab; Westergaard assumes a semi-circular load distribution, while the finite element model uses a rectangular contact area.

\subsection{OVERLAY SYSTEM}

1. Stress results between the finite-element model and the Portland Cement Association method are in good agreement. However, these stress values are low compared to the observed ones. The reason is perhaps because of the effect of the transverse shear. The transverse shear, for the slab dimensions used, is fairly high and should not be neglected.

2. The maximum stress decreases with the increase in the radius of the bearing area. This statement is valid for both the overlay and underlay stress behavior.

3. The equivalent radius of bearing area concepts suggested by the author gives a good approximation of the actual stress behavior in the overlay slab.

4. The stresses results computed by the ILLI-SLAB program for the underlay are slightly higher than the observed ones. The 
increase in the magnitude of the stress in the overlay slab due to the effect of the transverse shear may cause a reduction of stress in the underlay.

\subsection{SUGGESTIONS FOR FUTURE WORK}

1. A comprehensive approach for the estimation of error in stress and deflection calculations in pavements, and due to the variational characteristic of the material properties, should be advanced.

2. Stress analysis for the single layer concrete pavement should be further investigated for the case when a full circular load is applied at the edge of the pavement.

3. Tests should be conducted on a wider range of ratios of existing pavement and overlay slab thicknesses.

4. Further verification of the equivalent radius of the bearing area concept is recommended.

5. A theoretical approach to the analysis of an overlay system based on deflection criteria should be investigated.

6. The magnitude of the stress in the underlay should be theoretically analyzed with respect to the equivalent radius of bearing concept.

7. The effect of actual load in redistributing itself on the overlay and underlay pavements should be analyzed. 


\section{REFERENCES}

1. Ahlborn, Gale 1972. "Elastic Layered System with Normal Loads." The Institute of Transportation and Traffic Engineering, University of California, Berkeley, California, May.

2. American Concrete Institute 1967. "Design of Concrete Overlays for Pavements," Journal of the American Concrete Institute, Vol. 64, August, pp. 470-474.

3. Burmister, D. M. 1943. "The Theory of Stresses and Displacements in Layered Systems and Applications to the Design of Airport Runways," Highway Research Board, Proceedings, Vol. 23, pp. $126-149$.

4. Childs, L.D., 1963. "Tests of Concrete Pavement Slabs on Cement-Treated Subbases," Record No. 60, Highway Research Board, pp. 39-58.

5. Childs, L.D. 1967. "Cement-Treated Subbases for Concrete Pavements," Record No. 189, Highway Research Board, pp. 19-43.

6. Darter, N.I., B.F. McCullough and J.L. Brow 1972. "Reliability Concepts Applied to the Texas Flexible Pavement System," Highway Research Record, No. 407, pp 146-161.

7. Freudenthal, A.M., J. Garretts and M. Shinozwka 1966. "The Analys is of Structural Safety," Journal of The Structural Division, American Society of Civil Engineers, Vol 92, Feb.

8. Gillete, R.W. 1965. "Performance on Bonded Concrete Overlays," American Concrete Institute, Proceedings, Vol 60, No. 1, Jan.

9. Hank, R.J., and F.H. Scrivner 1948. "Some Numerical Solutions of Stresses in Two and Three-Layered Systems," Highway Research Board, Proceedings, Vol 28.

10. Hutchinson, R. 1966. "Basis for Rigid Pavement Design for Military Airfields" Corps of Engineers, Ohio River Division Laboratories, Misc Paper 5-7, May.

11. Kennedy, T.W. 1976. "Elastic and Stochastic Characteristics of Concrete for Rigid Pavement Design," Transportation Research Record No. 572, Transportation Research Board.

12. Kher, R.K., and M.I. Darter 1973. "Probabilistic Concepts and Their Application to AASHO Interim Guide for Design of Rigid Pavements," Record No. 466, Highway Research Board. 
13. Lal1, B. 1969. "Concrete Overlay of Concrete Pavement," a dissertation submitted in partial fulfillment of the requirements for the degree of Doctor of Philosophy (Highways) to University of Birmingham, Edgbaston, United Kingdom.

14. Lall, B. and G. Lees 1983. "Analys is of Stresses in Overlay-Pavement-Earth Systems," a paper presented at the 62nd Annual Meeting of the Transportation Research Board held in Washington, D.C., Jan.

15. Lepper, H.G. and Kim, J.B. 1963. "Test of Reinforcement Splices for Cont inuously-Reinforced Concrete Pavements," Record No. 60, Highway Research Board.

16. McComb, R.A. and Labra, J.J. 1974. "A Review of Structual Evaluation and Overlay Design for Highway Pavements," Federal Highway Administration, Pavement Rehabilitation: Proceedings of a Workshop, Report No. FHWA-RD-74-60, June.

17. McCullough, B.F. and Monismith 1970. "A Pavement Overlay Design System Considering Wheel Loads, Temperature Changes and Performance," Record No. 327, Highway Research Board.

18. Mellinger, F.M. 1963. "Structural Design of Concrete Overlays," American Concrete Institute, Journal of, Feb.

19. Peattie, K.R. and A. Jones 1962. "Surface Deflection of Road Structures," Symposium on Road Test for Pavement Design, Proceedings, Lishbon.

20. Portland Cement Association 1965. "The Design and Construction of Concrete Resurfacing for 0ld Pavements." PCS, No 15, 115. 01P.

21. Ray, G.K. 1964. "History and Development of Concrete Pavement Design," Journal of the Highway Division, The American Society of Civil Engineers, Proceedings, Vol. 90, Jan.

22. Ray, G.K. 1977. "Concrete in Transportation Construction," Journal of the Transportation Division, The American Society of Civil Engineers, Proceedings, Vol 103, Sept.

23. Tabatabaie, A.M. and E.J. Barenberg 1980. "Structural Analys is of Concrete Pavement Systems, "Journal of the Transportation Division, The American Society of Civil Engineers, Proceedings, Vol 106, Sept.

2.4. Teller, L.W. and E.C. Sutherland 1935, 1936, 1943. "The Structural Design of Concrete Pavements," Public Roads.

Part 1-1935A. A Description of the Investigation, Vol. 16, No. 8, October. 
Part 2 - 1935B. Observed Effects of Variation in Temperature and Moisture on the Size, Shape and Stress Resistance of Concrete Pavement Slabs, Vol 16, No. 9, November.

Part 3 - 1935C. A study of Concrete Pavement Cross Sections, Vol 16, No. 10, December.

Part 4 - 1936. A Study of the Structural Action of Several Types of Transverse and Longitudinal Joint Desing, Vol 17, Nos 7 and 8, September-October.

Part 5 - 1943. An Experimental Study of Westergaard Analysis of Stress Conditions in Concrete Pavement Slabs and Uniform Thickness, Vol 28, No. 8, Apri1-May-June.

25. Timms, A.G. 1963. "Evaluating Subgrade Friction-Reducing Mediums for Rigid Pavements," Record No. 60, Highway Research Board.

26. Treybig, J.H., McCullough, B.F., Smith, R.P. and H.V. Quintus 1977. "Overlay Design and Reflection Cracking Analysis for Rigid Pavement," Federal Highway Administration, Report No. FHWA-RD-77-66, August.

27. Ullidtz, P. and K.R. Peattie 1980. "Pavement Analys is by Programmable Calculators," Journal of the Transportation Division, The American Society of Civil Engineers, Proceedings, Vol 106, Sept., pp. 581-597.

28. Vallerga, B.A. and B.F. MuCullough 1969. "Pavement Evaluation and Design for Jumbo Jets," Journal of the Transportation Division, The American Society of Civil Engineers, Proceedings, Vol 95, November.

29. Vaswani, N.K. and J. Krishna 1967. "Pavement Performance as a Basis for Design," Journal of the Highway Division, The American Society of Civil Engineers, Proceedings, Vol 93, November.

30. Weiss, R.A. 1979. "Pavement Evaluation and Overlay Design: A Method that Combines Layered-Elastic Theory and Vibratory Nondestructive Testing," Report No. 700, Transportation Research Board, pp. 20-34.

31. Westergaard, H.M. 1926. "Stresses in Concrete Pavements Computed by Theoretical Analysis," Public Roads, Vol 7, No. 2, April.

32. Westergaard, H.M. 1948. "New Formulas for Stress and Deflection in Concrete Airfields," The American Society of Civil Engineers, Transactions, Vol. 113.

33. Yoder, E.J. and N.W. Witczak 1975. "Principles of Pavement Design," Second Edition, John Wiley and Sons, Inc. 